University of Warwick institutional repository: http://go.warwick.ac.uk/wrap This paper is made available online in accordance with publisher policies. Please scroll down to view the document itself. Please refer to the repository record for this item and our policy information available from the repository home page for further information.

To see the final version of this paper please visit the publisher's website. Access to the published version may require a subscription.

Author(s): Kostas Koufopoulos

Article Title: Optimal securities under adverse selection and moral hazard

Year of publication: 2009

Link to published version:

http://dx.doi.org/10.1016/j.jmateco.2009.03.003

Publisher statement: None 


\title{
Optimal Securities under Adverse Selection and Moral Hazard
}

\author{
Kostas Koufopoulos*
}

This version: August 2008

\begin{abstract}
We consider project financing under adverse selection and moral hazard and derive several interesting results. First, we provide an explanation of why good firms issue both debt and underpriced equity (even if the bankruptcy and agency costs of debt are zero). Second, we show that, in the presence of moral hazard, adverse selection may induce the conversion of negative into positive NPV projects leading to an improvement in social welfare. Third, we provide a rationale for the use of warrants. We also show that a debtwarrant combination can implement the optimal contract. Our results have a number of testable implications.
\end{abstract}

Key Words: Adverse Selection, Capital Structure, Moral Hazard

JEL classification: D82, G32

\footnotetext{
* University of Warwick, Warwick Business School; Kostas.Koufopoulos@wbs.ac.uk. I would like to thank numerous seminar participants, Margaret Bray, Antoine Faure-Grimaud, Jean-Charles Rochet, David Webb and especially Sudipto Bhattacharya and David de Meza for exceptionally helpful comments.
} 


\section{Introduction}

A large part of the securities issued by firms when they seek outside financing incorporate an option feature which provides the buyer with the right to buy the firm's shares at a prespecified price. In their attempt to raise funds at better terms, firms have used several option-like securities. However, two particular securities are the most widely used: convertible debt and debt-warrant combinations. In the case of convertible debt, if conversion takes place then the debtholder exchanges the face value of debt with a prespecified number of shares. In other words, the exercise price of the option coincides with the face value of debt. In debt-warrant combinations the exercise price of the option can be determined separately from the face of debt and in most cases it is different. That is, convertible debt is a special case of a debt-warrant combination that obtains when the exercise price of the warrant equals the face value of debt. Although debt-warrant combinations constitute a considerable fraction of these issues, the theoretical corporate finance literature has focused on convertible debt and paid little attention to debt-warrant combinations. ${ }^{1}$ Existing models offer various explanations of why firms issue convertible debt but they do not justify the necessity for the use of warrants. ${ }^{2}$

In this paper, we construct a simple asymmetric information model that provides a rationale for the use of warrants. We abstract from taxes, financial distress, bankruptcy and other agency costs. We consider a model involving both adverse selection and (effort) moral hazard. There are two types of firms (projects): good (G), bad (B). Given identical effort levels, the success probability is the same for both types of projects but in case of success the good project's return is higher (first-order stochastic dominance). ${ }^{3}$ In the event of failure, regardless of its type, the project's return is zero. The entrepreneur can increase the success probability by exerting costly effort. Regardless of the project's type, if the entrepreneur exerts effort the net present value (NPV) of his project exceeds the cost of effort whereas if he shirks the project has negative NPV. That is, exerting effort is socially efficient for both types. Both the project's type and the entrepreneur's action are private information of the entrepreneur.

As a benchmark, we first consider the case where moral hazard is not binding (pure adverse selection). In this case, the role of securities is to convey socially costless information about the type of the project. Equity issued by the G-type is more valuable whereas debt issued by both types is equally valuable. ${ }^{4}$ So, if the G-type issues some equity the B-type will mimic him and so in the resulting pooling equilibrium the G-type will subsidize the B-type through the mispricing of equity. However, in any pooling equilibrium where some mispriced equity is issued, the G-type has an incentive to deviate by issuing more debt (the relatively less valuable for him security). By doing so, he can

\footnotetext{
${ }^{1}$ For example, de Roon and Veld (1998) report that about 30 percent of the convertible securities issued by Dutch companies from 1976 to 1996 were debt-warrant combinations.

${ }^{2}$ Green (1984), Constantinides and Grundy (1989), Stein (1992), Casamatta (2003), Cornelli and Yosha (2003) and Schmidt (2003) provide different rationales for the use of convertible debt.

${ }^{3}$ This assumption is made for simplicity. All main results go through if instead we assume that, given identical effort levels, the success probability of good firms is greater (first-order stochastic dominance).

${ }^{4}$ The market value of debt depends only on the success probability whereas the value of equity depends on both the success probability and the return in case of success which greater for the G-type. Thus, our results go through even if, given the effort level, the success probability of the G-type is higher. The only difference is that in this more general case debt will also be mispriced but less than equity.
} 
credibly signal his type, reduce the mispricing and increase his expected return. As a result, no pooling equilibrium where some equity is issued can sustain. That is, the Gtype issues just debt to avoid selling an underpriced security (equity).

The introduction of moral hazard into an adverse selection framework has significant effects both on the combinations of the securities issued in equilibrium and their pricing. The distinguishing feature of this paper is the existence of a pooling equilibrium involving cross-subsidization across types and the issue of both debt and equity (warrants). This pooling equilibrium reflects a trade-off between information revelation and effort incentives. The securities issued by the G- and B-type are priced as a pool. Although, because of free entry of financiers, debt and equity (warrants) are fairly priced collectively, at individual level equity is mispriced. In fact, it is precisely this mispricing that provides the more prone to shirking type (B-type) with the subsidy necessary to induce him to choose the socially efficient high-effort level. ${ }^{5}$

Consider, for example, the case where the financial instruments available are debt and equity. In this case, in the pooling equilibrium the G-type subsidizes the B-type through the mispricing of equity. As we have seen, under pure adverse selection, the G-type would have issued just debt to eliminate this mispricing. However, in the presence of moral hazard, the elimination of the subsidy destroys the B-type's effort incentives. The B-type shirks and the aggregate expected return falls. As a result, the financiers, in order for them to break even, ask for a higher interest rate on debt. This additional cost of debt exceeds the underpricing of equity. That is, since he cannot reveal his type, the G-type accepts to issue just enough equity to induce the B-type to exert effort because the resulting increase in his net expected return (due to the lower interest rate on debt) more than offsets the cost of the subsidy (the adverse selection cost of issuing equity).

Notice that as the proportion of the B-type increases, the fraction of equity needed to provide the B-type with the subsidy necessary to induce him to work also increases (the debt-equity ratio falls). The maximum subsidy is provided when only equity is issued. If the financial instruments available are debt and equity, for a sufficiently high proportion of the B-type, the pooling equilibrium where both types exert effort collapses although the G-type would have exerted effort even if a higher fraction of equity was issued (more subsidy was given to the B-type).

Warrants can help us restore the existence of the socially efficient pooling equilibrium. In absolute terms, the value of warrants issued by either type falls with the exercise price by the same amount. However, because in case of success the return of the G-type exceeds that of the B-type, the warrant value falls with the exercise price proportionately faster for the B-type. As a result, the B-type is willing to increase faster the fraction of equity offered to the financier than the G-type while still exerting effort. That is, the warrant payoff function can be steeper than the equity payoff function without violating the B-type effort incentive constraint. This implies that the difference between the total value of the warrants issued by the G- and B-type can exceed the

\footnotetext{
${ }^{5}$ If funds are offered at fair terms, the G-type exerts effort whereas the B-type shirks. Hence, the B-type's project NPV is negative and so, if his type is revealed, no rational financier offers funds to him. Therefore, in order to receive financing, the B-type will always mimic the G-type. Because, in case of success, the return of the good project exceeds that of the bad one, a given increase in the success probability leads to a greater increase in the net expected return of a good entrepreneur. As a result, good entrepreneurs may exert effort even if they subsidize the bad entrepreneurs.
} 
corresponding difference of equity values consistent with both types working. Therefore, by choosing a sufficiently high exercise price, we can provide the B-type with the subsidy necessary to induce him to work when the proportion of the G-type is so low that the socially efficient pooling equilibrium breaks if a debt-equity combination is used.

That is, through the appropriate choice of their exercise price, warrants allow for the implementation of the socially efficient outcome even if this is not possible when we restrict ourselves to debt, equity and/or convertible debt. ${ }^{6}$ This result provides a rationale for their use. Finally, we show that a debt-warrant combination can implement the optimal contract as a competitive equilibrium.

Our results have several interesting implications. First, they provide an explanation of why good firms issue both debt and underpriced equity even though the bankruptcy and other agency costs associated with debt are zero. The issue of equity, through its mispricing, provides bad entrepreneurs with the incentives to work whereas debt is used to reduce the subsidy to the minimum required. What is more, because it relaxes the moral hazard constraint, the cross-subsidization occurring in this pooling equilibrium is socially beneficial. It results in the conversion of negative into positive NPV projects leading to an improvement in the aggregate expected returns and social welfare.

Our results have also some implications for empirical testing: i) The higher the proportion of low-profitability (B-type) firms, the higher the fraction of funds raised through equity. This prediction is consistent with the findings in Fama and French (2005). ${ }^{7}$ ii) As the proportion of low-profitability firms rises, more funds should be raised through the issue of warrants. To the best of our knowledge, this prediction has not been tested yet. iii) Because the G-type equity is more valuable, ex post, good firms have lower debt-equity ratios (market values). This negative relation between leverage and profitability has been documented by several empirical studies (e.g., Titman and Wessels (1988), Rajan and Zingales (1995) and Fama and French (2002)). ${ }^{8}$

\section{Related Literature}

This paper is more closely related to papers that try to explain the use of securities with option features based on some form of informational asymmetry: moral hazard (agency models) or pure adverse selection models.

In the celebrated Jensen and Meckling (1976) paper firms issue both debt and equity to minimize the sum of agency costs of these two securities. The agency cost of equity arises from the conflict of interest between management and outside shareholders. The

\footnotetext{
${ }^{6}$ In our model, convertible debt does not improve on a debt-equity combination. If convertible debt is used, the exercise price of the option coincides with the face value of debt. This implies that if debt is converted into equity, the payment to the shareholders consists only of the project's return. As a result, the maximum proportion of equity offered to the financiers consistent with the B-type working is exactly the same as under a debt-equity combination. In contrast, if a debt-warrant combination is used, the total payment to the shareholders, if the option is exercised, consists of two components: i) the project's return and ii) the difference between the warrant exercise price and the face value of debt (which can be positive). Hence, the maximum proportion of equity issued consistent with the B-type working can be greater than under a debtequity combination.

${ }^{7}$ Fama and French (2005) report that during the period 1973-2002 the proportion of high-profitability firms declines while the fraction of funds raised through equity increases.

${ }^{8}$ Provided the securities issued are risky, our results hold true even if the two types of firms have identical projects but the good firms have assets in place that generate higher expected profits.
} 
agency cost of debt stems from the conflict of interest between existing shareholders (managers) and would-be debtholders. The issue of debt induces the managers to undertake riskier projects that reduce the value of debt and transfer wealth from debtholders to shareholders (asset substitution problem). ${ }^{9}$

In this context, Green (1984) focuses on the asset substitution problem and develops a rationale for the use of convertible debt. Convertible debt reverses the convex shape of levered equity over the upper range of the firm's returns (where conversion takes place). As a result, it alters the incentives of the shareholders to take risk and so mitigates the asset substitution problem.

Pure adverse selection models emphasize the signalling role of the financing decisions of the firm. Brennan and Kraus (1987) show that, under second-order stochastic dominance, fully revealing equilibria can be obtained by issuing convertible debt. Constantinides and Grundy (1989) prove that, under first-order stochastic dominance, the issue of convertible debt coupled with equity repurchases leads to full information revelation. However, it should be noted that, in the absence of bankruptcy or financial distress costs, pure adverse selection models cannot explain why good firms issue equity even if it is underpriced.

Stein (1992) introduces financial distress costs and provides another justification for the use of convertible debt. In a three-type model, he obtains a fully separating equilibrium where the good type issues debt, the medium type issues convertible debt that is always converted into equity, and the bad type issues equity directly to avoid incurring the distress costs. In this separating equilibrium all firms invest and no distress costs are borne in equilibrium. If convertible debt were not used, this separating equilibrium would not, in general, exist and a situation similar to that described in Myers and Majluf (1984) would arise.

The justifications provided by Green (1984), Brennan and Kraus (1987), and Constantinides and Grundy (1989) for the use of convertible debt rely on the fact that its payoff is concave in the firm's returns for low values of returns and convex for higher values. ${ }^{10}$ In Stein (1992), the usefulness of convertible debt stems from the presence of financial distress costs and the inability of a bad firm to force conversion. In our model, the mechanism at work is different. First, it does not depend on financial distress costs. Second, in our case, convertible debt does not improve on a debt-equity combination. Our mechanism relies on the fact that the warrant exercise price can be greater than the face value of debt. By choosing an exercise price higher than the face value of debt, we can make the difference between the total value of the warrants issued by the G- and B-type greater than the corresponding difference of equity values and provide the B-type with the subsidy necessary to induce him to work when the proportion of the G-type is so low that the socially efficient pooling equilibrium breaks if warrants are not available.

Notice that if types were observable, the B-type would not receive financing and so both investment and social welfare would be lower. These results contrast with those of pure adverse-selection models. In Myers and Majluf (1984) adverse selection leads firms

\footnotetext{
${ }^{9}$ Notice that in our model there is no conflict of interests between shareholders and debtholders (no asset substitution problem) which, given the agency cost of equity, is the driving force of the coexistence of debt and equity in Jensen and Meckling.

${ }^{10}$ For the same reason, convertible debt is used to resolve informational problems in the context of venture capital financing (see, for example, Casamatta (2003), Cornelli and Yosha (2003) and Schmidt (2003).
} 
to forego positive NPV projects whereas in de Meza and Webb (1987) it encourages firms to undertake negative NPV projects. Hence, in either case social welfare is lower than under full information about types. The key to this difference is that in the presence of (effort) moral hazard the cross-subsidization taking place in the pooling equilibrium relaxes this additional constraint and so it can be beneficial. In contrast, in these two pure adverse selection models there is no channel through which the cross-subsidy can have positive effects but it may have negative ones.

This paper is organized as follows. Next section describes the basic framework and develops the analytical tools. Section 4 provides some general results about the existence and the type of the equilibria where funds are offered. Section 5 analyzes the roles of debt and equity under pure adverse selection and adverse selection cum moral hazard. The role and usefulness of warrants are explored in Section 6. In Section 7, we show that, in the adverse selection cum moral hazard case, a debt-warrant combination can implement the optimal contract. Some brief concluding remarks are provided in Section 8.

\section{The Model}

We consider a simple one-period model of financing involving both adverse selection and effort moral hazard. There are two dates, 0 and 1, and one homogeneous (perishable) good which can be used either for consumption or investment purposes. There are also two groups of agents: entrepreneurs and financiers. Both groups of agents consume only at date 1. Each entrepreneur has an indivisible project but no initial wealth. All projects require the same fixed initial investment $\mathrm{I}$, at date 0 . Since the entrepreneurs have no initial wealth, they need to raise I from the market. Each financier has a very large amount of initial wealth and can lend at zero interest rate. For simplicity, we assume that there are just two financiers involved in Bertrand competition.

Both the entrepreneurs and the financiers are risk neutral. Also, there are no taxes, no bankruptcy or financial distress costs. Finally, there is no conflict of interest between managers and entrepreneurs. In fact, firms are run by entrepreneurs.

Investment takes place at date 0 . Returns are realized at date 1 and are observable and verifiable. There are two states of nature: Success, Failure. If a project succeeds it yields $X_{i}$. In case of failure, all projects yield 0 regardless of the entrepreneur's type. There are two types of entrepreneurs (projects), G (good) and B (bad), with respective proportions in the population $\lambda$ and $1-\lambda, 0 \leq \lambda \leq 1$.

The success probability of a project, denoted by $\pi\left(C_{i}\right)$, depends on the effort level that each entrepreneur chooses privately. There are two effort levels: Low (shirking), High (working). If an entrepreneur exerts effort $\left(C_{i}=C\right)$, he incurs a utility cost of $C$ and his success probability $\pi\left(C_{i}\right)$ is $\pi_{C}$. If he shirks $\left(C_{i}=0\right)$, his utility cost is 0 but his success probability $\pi\left(C_{i}\right)$ is $\pi_{0}$, where $\pi_{C}>\pi_{0}$. Given identical effort levels, the success probability is the same for both types of projects but in case of success the good project's return is higher: $X_{G}>X_{B}$ and $\pi_{j}^{G}=\pi_{j}^{B}=\pi_{j}, j=C, 0 .{ }^{11}$

\footnotetext{
${ }^{11}$ This assumption is made because it simplifies the analysis without losing any insight. All main results go through under the more general assumption $\pi_{j}^{G} \geq \pi_{j}^{B}$ (first-order stochastic dominance).
} 
If the high effort level is chosen, the net present value (NPV) of both types of projects exceeds the cost of effort. In contrast, if shirking is chosen, neither project is economically viable (both types of projects have strictly negative NPV). That is,

Assumption 1: $\pi_{C} X_{i}-I>C>0>\pi_{0} X_{i}-I, \quad i=G, B$

Assumption 1 also implies $\left(\pi_{C}-\pi_{0}\right) X_{i}>C,(i=G, B)$. That is, the choice of the high effort level by either type leads to an increase in the net social surplus and so is socially efficient.

For expositional purposes, we begin by restricting the financing instruments available to entrepreneurs to debt and outside equity. Debt claims are zero-coupon bonds that are senior to equity.

A contract $A=(\alpha, D)$ provides the entrepreneur with the required amount of funds, I, in return for a combination of debt of face value $D$ and a proportion of equity of the project $\alpha, \quad 0 \leq \alpha \leq 1, \quad D \geq 0$.

Therefore, given risk neutrality and limited liability, the entrepreneurs seek to maximize:

$$
U_{i}\left(X_{i}, \alpha_{i}, D_{i}, C_{i}\right)=\pi\left(C_{i}\right) \operatorname{Max}\left[\left(1-\alpha_{i}\right)\left(X_{i}-D_{i}\right), 0\right],{ }^{12} \quad i=G, B
$$

where $U_{i}$ is the expected utility of an entrepreneur of type i when choosing the contract $A_{i}=\left(\alpha_{i}, D_{i}\right)$.

At date 0 , when the contract is signed, the entrepreneurs know their own type but the financiers cannot observe either the type of each individual entrepreneur or verify the actions (choice of effort level) of the entrepreneurs applying for funds. The financiers do, however, know the proportion of each type in the population of entrepreneurs and the nature of the investment and moral hazard "technology". The financiers also wish to maximize their expected profit. The expected profit, $P_{F}$, of an financier offering a contract $(\alpha, D)$, given limited liability, is given by:

$$
P_{F}=\pi\left(C_{i}\right)\left\{\operatorname{Max}\left[\alpha\left(X_{i}-D\right), 0\right]+\operatorname{Min}\left(X_{i}, D\right)\right\}-I, \quad i=G, B
$$

\subsection{Effort Incentive Constraints}

Let us first consider the moral hazard problem an entrepreneur of type i faces. A given contract $(\alpha, D)$ will induce the high effort level if

$$
\left(\pi_{C}-\pi_{0}\right)(1-\alpha)\left(X_{i}-D\right) \geq C, \quad i=G, B
$$

\footnotetext{
${ }^{12}$ Whenever the Max or Min operators are irrelevant they will be suppresed.
} 


$$
\text { or } \quad \Delta_{i}=(1-\alpha)\left(X_{i}-D\right)-c \geq 0, \quad \text { where } \quad c \equiv \frac{C}{\pi_{C}-\pi_{0}}, \quad i=G, B
$$

The left-hand side of (3) is the increase in the entrepreneur's net expected return from exerting effort and the right-hand side is the cost of effort. Let $I C F_{i}$ be the locus of combinations $(\alpha, D)$ such that $\Delta_{i}=0$. This locus divides the $(\alpha, D)$ space into two regions: On and below the $I C F_{i}$ locus the entrepreneurs of type i exert effort (this is the set of effort incentive compatible contracts, $I C_{i}$ ) and above it they do not. Because, in case of success, the return of the good project exceeds that of the bad one ( $X_{G}>X_{B}$ ), a given increase in the success probability leads to a greater increase in the net expected return of a good entrepreneur. As a result, good entrepreneurs can be more easily incentivized to exert effort. That is, the G-type's set of effort incentive compatible contracts is strictly greater than that of the B-type ( $I C_{B} \subset I C_{G}$ ). Lemma 1 summarizes the key features of the moral hazard "technology".

Lemma 1. In the $(\alpha, D)$ space:

a) $I C F_{i}$ are downward sloping and strictly concave. Also, at any $(\alpha, D)$ pair, $I C F_{G}$ is flatter than $I C F_{B}$.

b) $I C F_{B}$ lies strictly below $I C F_{G}$. That is, $I C_{B} \subset I C_{G}$.

c) Neither $I C_{B}$ nor $I C_{G}$ is empty.

Proof: See the Appendix (See also Figure 1).

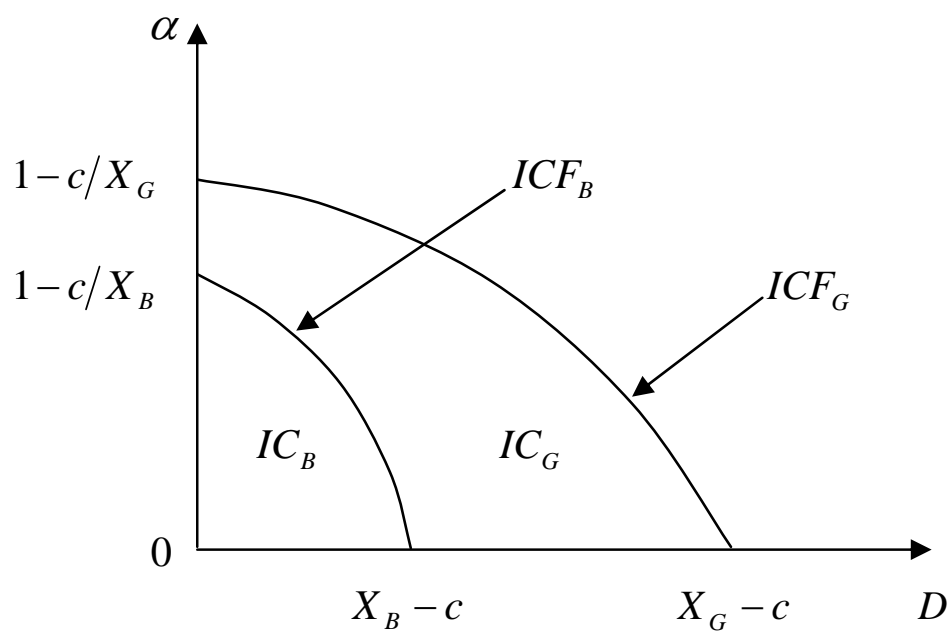

Figure 1. Effort incentive constraints. 


\subsection{Indifference Curves}

The family of indifference curves of type i can be derived from Eq. (1). It should be noted that the shape of the indifference curves is independent of the probability of success. ${ }^{13}$ As a result, no indifference curve of type i crosses $I C F_{i}$ and therefore the indifference curves do not exhibit kinks in the $(\alpha, D)$ space. For each type, one of the indifference curves coincides with the corresponding ICF.

Lemma 2. Let $U_{i}$ denote the family of indifference curves of type i, and $u_{i}$ denote a member of this family. In the $(\alpha, D)$ space, for $0 \leq \alpha<1$ and $0 \leq D<X_{i}$

a) $u_{i}$ are downward sloping and concave.

b) At any $(\alpha, D)$ pair, $u_{G}$ is flatter than $u_{B}$ and so the indifference curves of G- and Btype cross only once.

Proof: See the Appendix.

That is, the marginal rate of substitution of debt for equity of the G-type is greater than that of the B-type. Intuitively, equity is more valuable for the G-type whereas debt is equally valuable for both types. ${ }^{14}$ As a result, the G-type is willing to accept a greater increase in $D$ in exchange for a given reduction in $\alpha$ than the B-type. Technically, the single-crossing condition is satisfied. Also, the closer to the origin an indifference curve, the higher the expected utility.

\subsection{Zero-profit Curves}

The expected profit of a financier offering a contract $(\alpha, D)$ is given by Eq. (2). It is clear that the expected profit depends crucially on the effort level chosen (through the project success probability). So, if a zero-profit curve crosses the corresponding effort incentive frontier ICF, it will exhibit a discontinuity because the success probability changes discontinuously when the entrepreneurs change their effort level. However, given limited liability and the assumption that both types of projects have negative NPV when the low effort level is chosen $\left(\pi_{0} X_{i}-I<0\right)$, the zero-profit curves corresponding to shirking $\left(\pi=\pi_{0}\right)$ do not exist. Any contract $(\alpha, D)$ financing a shirking entrepreneur is lossmaking and no rational financier will offer it. Therefore, zero-profit curves can exist only if the high effort level is chosen (by at least one of the two types of entrepreneurs).

More specifically, the zero-profit curve corresponding to the i-type $\left(Z P_{i}\right)$ exists only if the i-type chooses the high effort level (his effort incentive constraint is satisfied) when he receives funds at fair terms. ${ }^{15}$ In other words, the existence of a zero-profit curve

\footnotetext{
${ }^{13}$ This is due to fact that in the event of failure the return is zero.

${ }^{14}$ The market value of debt depends only on the success probability (which is equal for both types) whereas the value of equity also depends on the return in case of success which greater for the G-type.

${ }^{15}$ By assumption 1, both types of projects have strictly positive NPV when the high effort level is chosen and negative NPV when the entrepreneurs opt for shirking.
} 
$\left(Z P_{i}\right)$ requires that it belong to the corresponding set of effort incentive compatible contracts $\left(I C_{i}\right)$. Given the investment and moral hazard technology, if both types receive funds at fair terms three different cases may arise: i) the effort incentive constraint is not binding for either type, ii) it is not binding for the G-type but is violated for the B-type, and iii) it is violated for both types. ${ }^{16}$ Conditional on the choice of the high effort level there exist three zero-profit curves: that corresponding to the G-type $\left(Z P_{G}\right)$, to the B-type $\left(Z P_{B}\right)$, and the pooling zero-profit curve $\left(P Z P_{H}\right) \cdot{ }^{17}$ Lemma 3 summarizes the key properties of the zero-profit curves and their relationship with the corresponding indifference curves and effort incentive frontiers. Subsequently, Lemma 4 provides the conditions for the existence of the individual zero-profit curves $Z P_{G}$ and $Z P_{B}$.

Lemma 3. In the $(\alpha, D)$ space,

a) All $Z P_{i}, P Z P_{H}$ are downward sloping and strictly concave.

b) $Z P_{G}$ and $Z P_{B}$ intersect at $\alpha=0$. For $\alpha>0, Z P_{G}$ lies entirely below $Z P_{B}$.

c) $I C F_{i}, u_{i}$, and $Z P_{i}$ never cross each other, $i=G, B$.

Proof: See the Appendix.

Intuitively, in Part (b), since both have the same success probability, given its face value, the debt issued by both types is equally valuable. Thus, if both issue only debt, zero profit for financiers requires the issue of the same level of debt. However, if equity is also issued, since the G-type equity is more valuable, a financier who just breaks even would ask for a lower proportion of equity if he offered funds to the G-type than to the B-type (given the debt level). That is, $Z P_{G}$ lies below $Z P_{B}$ at any positive level of equity issued.

Also, since all three, zero-profit curves, indifference curves, and effort incentive frontiers corresponding to type i have the same slope, they never cross. One of the indifference curves coincides with the corresponding zero-profit curve. However, the location of the zero-profit curve relative to the corresponding effort incentive frontier is the key determinant for the existence of the former.

Lemma 4. Suppose both types obtain funds at fair terms, then

a) If $\pi_{C} X_{i}-I \geq \pi_{C} C, i=G, B$, then both $Z P_{G}$ and $Z P_{B}$ exist.

b) If $\pi_{C} X_{G}-I \geq \pi_{C} C, \pi_{C} X_{B}-I<\pi_{C} C$, then only $Z P_{G}$ exists.

c) If $\pi_{C} X_{i}-I<\pi_{C} c, i=G, B$, then neither $Z P_{G}$ nor $Z P_{B}$ exists.

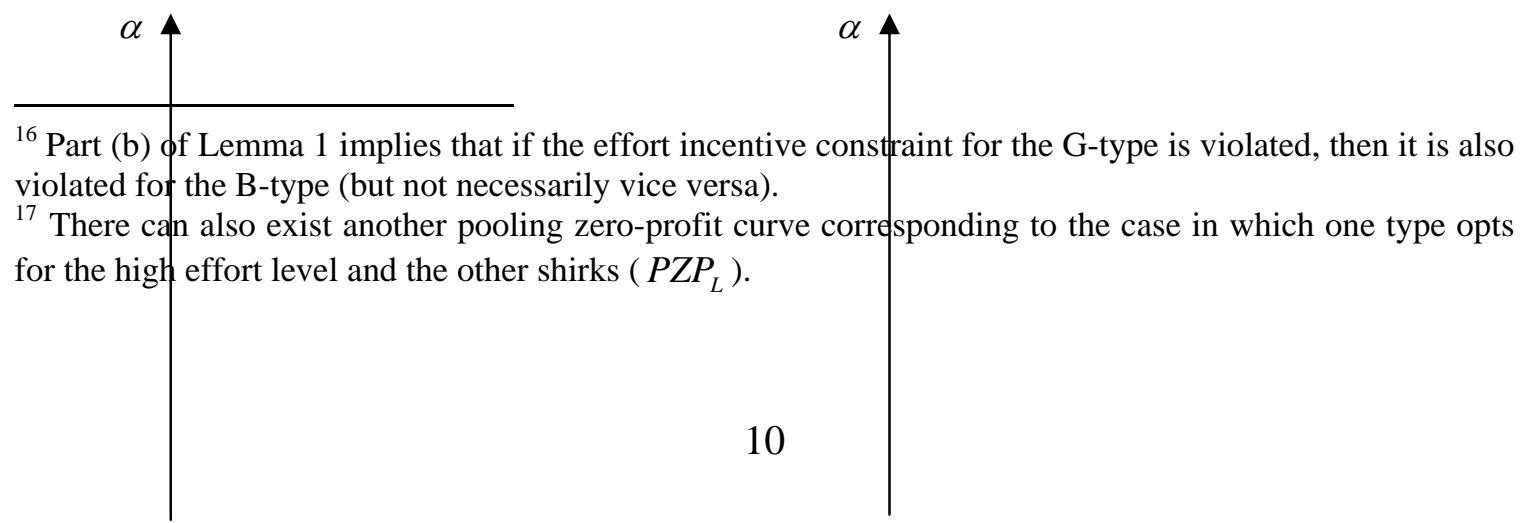




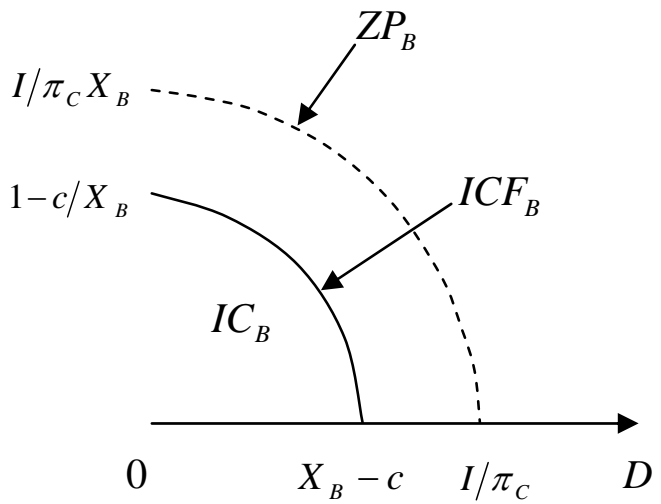

Panel A: B-Type

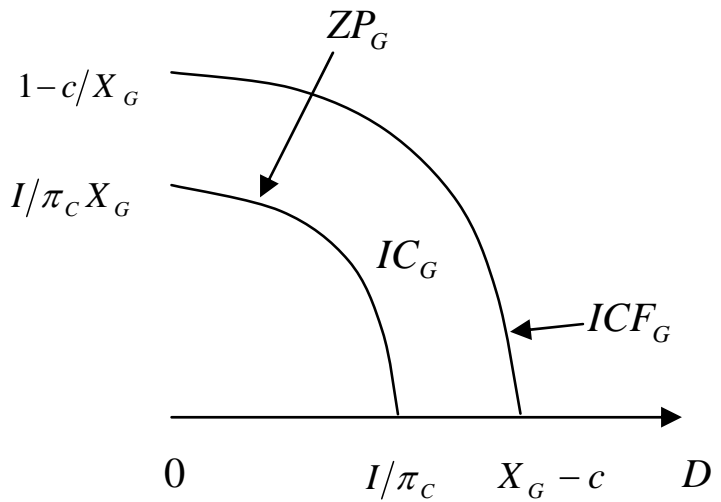

Panel B: G-Type

Figure 2. Effort incentive constraints and zero-profit curves.

Proof: See the Appendix.

Case (a) corresponds to pure adverse selection. Although moral hazard is present, because for both types the NPV $\left(\pi_{C} X_{i}-I\right)$ exceeds the "effective" cost of effort $\left(\pi_{C} c\right)$, it has no bite. If either type obtains funds at fair terms, he exerts effort and so the corresponding zero-profit curve exists. In Case (b), financing at fair terms implies that the effort incentive constraint of the G-type is satisfied but that of the B-type is violated $\left(Z P_{G}\right.$ belongs to $I C_{G}$ but $Z P_{B}$ lies outside $I C_{B}$ ). As a result, the G-type exerts effort and so $Z P_{G}$ exists whereas the B-type opts for shirking and $Z P_{B}$ does not exist. In Case (c), the NPV of the project falls short of the "effective" cost of effort for both types. Thus, both types opt for shirking and so no zero-profit curve exists. Figure 2 provides an illustration for Case (b).

\subsection{Equilibrium}

It is well-known that, in most cases, the equilibrium outcome in competitive markets with asymmetric information depends crucially on the game-theoretic specification of the strategic interaction between the informed and uninformed agents. Here, I assume that the financiers and the entrepreneurs play the following three-stage game due to Hellwig (1987):

Stage 1: The two financiers simultaneously offer contracts $(\alpha, D)$. Each financier may offer any finite number of contracts.

Stage 2: Given the offers made by the financiers, the entrepreneurs apply for (at most) one contract from one financier. If an entrepreneur's most preferred contract is offered by 
both financiers, the entrepreneur chooses each financier's offer with probability $1 / 2$. In the light of the contract chosen, the entrepreneur decides whether to work or shirk.

Stage 3: After observing the contracts offered by his rival and those chosen by the entrepreneurs, each financier decides which applications will accept or reject. If an application is rejected, the applicant does not receive funds.

This game structure rationalizes a Wilson equilibrium (1977) as a perfect Bayesian equilibrium. ${ }^{18}$ Unlike the two-stage screening game, it allows for the existence of a (interior) Nash pooling equilibrium when this pooling equilibrium Pareto-dominates any other equilibrium. $^{19}$

We only consider pure-strategy perfect Bayesian equilibria. A pair of contracts $\left(A_{G}, A_{B}\right)$ is an equilibrium if the following conditions are satisfied (in a pooling equilibrium $\left.A_{G}=A_{B}=A\right):{ }^{20}$

- No contract in the equilibrium pair implies negative (expected) profits for the financier. In other words, the financiers' participation or IR constraints are satisfied:

$$
\pi\left(C_{i}\right)\left\{\operatorname{Max}\left[\alpha\left(X_{i}-D\right), 0\right]+\operatorname{Min}\left(X_{i}, D\right)\right\} \geq I, \quad i=G, B
$$

- Profit maximization: No other set of contracts, if offered alongside the equilibrium pair at Stage 1, would increase a financier's expected profit.

\section{Types of Equilibria and Provision of Funds: General Results}

Because of Bertrand competition, any equilibrium involves zero expected profits for the financiers. This implies that any equilibrium contract must lie on one of the zero-profit curves. This, in turn, implies the following result:

Lemma 5. A separating equilibrium can exist only if both $Z P_{G}$ and $Z P_{B}$ exist. If either $Z P_{B}$ or $Z P_{G}$ or both do not exist, then no separating equilibrium exists. ${ }^{21}$

\footnotetext{
${ }^{18}$ This game is not unique in that respect. Many other games can be used to provide game-theoretic foundations to Wilson equilibrium. For example, if we swap stages 2 and 3 of the above game we can support the same pooling allocation as a sub-game perfect Nash equilibrium. The key for the implementation of this pooling allocation as a Nash equilibrium is that the commitment of the financiers to the contracts they offer is endogenous rather than exogenously imposed as in Rothschild and Stiglitz (1976). I employ this particular game because the focus of the paper is not on the implementation of incentive efficient allocations and the use of a well-known game facilitates the exposition.

${ }^{19}$ As shown by Diasakos and Koufopoulos (2008), if agents are allowed to choose the mechanism used for the allocation of resources, any equilibrium mechanism will implement the interim incentive efficient allocation that maximizes the expected utility of the highest-quality type. Also, there potentially exist many (infinite) mechanisms that can achieve the same outcome. In this paper, this allocation coincides with the pooling allocation which is the unique "reasonable" equilibrium of the three-stage used.

${ }^{20}$ We assume that if an entrepreneur is indifferent between investing and not he invests. Given that assumption and limited liability, the entrepreneurs' participation constraints are always satisfied.
} 
Proof: First, given limited liability, if funds are offered (whatever the terms they are offered at) both types of entrepreneurs will always accept them and undertake their project. Thus, there cannot exist a separating equilibrium where only one type invests. Suppose now there is a separating equilibrium in which the G-type chooses contract $\left(\alpha_{G}, D_{G}\right)$ and the B-type chooses contract $\left(\alpha_{B}, D_{B}\right)$. The contract chosen by the G-type must lie on the G-zero-profit line $\left(Z_{G}\right)$ and that chosen by the B-type on the B-zeroprofit line $\left(Z P_{B}\right)$. Therefore, a separating equilibrium can exist only if both zero-profit curves exist. If one (or both) of the zero-profit curves does not exist, a separating equilibrium cannot exist. Q.E.D.

Lemma 5 implies that in cases where one (or both) of the zero-profit curves does not exist, if there exists an equilibrium, it must be pooling. Proposition 1 summarizes these results.

Proposition 1. A separating equilibrium can exist only if $\pi_{C} X_{i}-I \geq \pi_{C} C, i=G$, B. If $\pi_{C} X_{i}-I<\pi_{C} C$, for either $i=B$, or $i=G, B$, then the resulting equilibria must be pooling.

The next general result concerns the conditions under which funds are provided.

\section{Proposition 2.}

a) If $\pi_{C} X_{i}-I \geq \pi_{C} c, i=G, B$, then both types of projects receive financing.

b) If $\pi_{C} X_{G}-I \geq \pi_{C} c, \pi_{C} X_{B}-I<\pi_{C} c$, then funds are offered to both types only if (a part of) either $P Z P_{H}$ or $P Z P_{L}$ exists.

c) If $\pi_{C} X_{i}-I<\pi_{C} c, i=G, B$, there exists a unique pooling equilibrium where no entrepreneur obtains funds (no project is undertaken).

Proof: In any equilibrium, funds are offered only along the zero-profit curves. Thus, in any equilibrium, the financiers will offer funds only if (a part of) a zero-profit curve exists.

a) By Lemma 4, both $Z P_{G}$ and $Z P_{B}$ exist. As a result, $P Z P_{H}$ also exists. Hence, regardless of the type of the equilibrium (separating or pooling) funds are offered.

b) By Lemma 5, in this case, only pooling equilibria can exist. However, the existence of pooling equilibria where funds are offered requires that (a part of) a pooling zeroprofit curve exists. Thus, (a part of) either $P Z P_{H}$ or $P Z P_{L}$ must exist. ${ }^{22}$

\footnotetext{
${ }^{21}$ Given that the entrepreneurs' participation constraints are always satisfied, the result in Lemma 5 holds true regardless of the form of the contracts.

22 (A part of) $P Z P_{H}$ exists if it belongs to the intersection of $I C_{B}$ and $I C_{G}$. Contracts offered along it are effort incentive compatible for both types. Thus, both types choose the high effort level and so it actually exists. If $P Z P_{H}$ does not belong to the intersection of $I C_{B}$ and $I C_{G}$, it does not exist. In such a case, (at least) one of the two types shirks contradicting the condition on which $P Z P_{H}$ is drawn. (A part of) $P Z P_{L}$
} 
c) By Lemma 4, neither $Z P_{G}$ nor $Z P_{B}$ exists. As a result, by Lemma 5, no separating equilibrium exists. Moreover, since neither $Z P_{G}$ nor $Z P_{B}$ exists, no pooling zeroprofit curve exists. If a financier offers funds to any entrepreneur, he will make losses. Therefore, no rational financier will do so (the financiers' participation constraints are violated). Q.E.D.

Notice that even in Case (c), if either type had chosen the high effort level he would have enjoyed a strictly positive expected utility (the difference between the NPV of the project and the cost of effort) instead of zero. However, due to moral hazard, the inducement of this choice is not feasible.

\section{Types of Equilibria and Methods of Financing: Specific Results}

Now that we have developed the analytical apparatus, we can go on to prove our main results. Subsection 5.1 examines the pure adverse selection case. In subsection 5.2 we consider the case where adverse selection and moral hazard interact.

\subsection{The Pure Adverse Selection Case}

It would be useful, as a benchmark, to first consider the pure adverse selection case (Case (a) of Lemma 4). In this case, as we have seen, no effort incentive constraint is binding if funds are offered at fair terms and so both zero-profit curves $Z P_{G}$ and $Z P_{B}$ exist. This, in turn, implies that the pooling zero-profit curve $P Z P_{H}$ also exists. Therefore, both separating and pooling equilibria can exist. More specifically,

Proposition 3. If $\pi_{C} X_{i}-I \geq \pi_{C} c, i=G, B$, there exists a pooling equilibrium where both types issue only debt as well as a continuum of separating equilibria where the Gtype issues only debt whereas the B-type issues a combination of debt and equity. In any equilibrium, the securities issued are fairly priced (See Figure A1).

Proof: See the Appendix

Under pure adverse selection, debt and equity are only used to convey information about the type of the project. Because equity issued by the G-type is more valuable whereas debt issued by both types is equally valuable, if the G-type issues some equity the B-type will mimic him and so in the resulting pooling equilibrium the G-type will subsidize the B-type through the mispricing of equity. Hence, in any pooling equilibrium where some equity is issued, the G-type has an incentive to deviate by issuing more debt. By doing so, he can credibly signal his type, reduce the cross-subsidization and increase his expected

exists if the following two conditions are satisfied: i) (A part of) it belongs to either $I C_{G}$ and ii) $\lambda \pi_{C} X_{G}+(1-\lambda) \pi_{0} X_{B} \geq I$. 
return (utility). As a result, no pooling equilibrium where some equity is issued can sustain. That is, the G-type issues just debt to avoid selling an underpriced security (equity). Given that, the B-type is indifferent between issuing just debt and any fairly priced combination of debt and equity. Therefore, the issue of equity signals a B-type.

\subsection{The Adverse Selection cum Moral Hazard Case}

In this subsection, we examine the case where the B-type NPV falls short of his "effective" cost of effort (Case (b) of Lemma 4). That is, if the B-type is offered funds at fair terms, his effort incentive constraint is violated and so the corresponding zero-profit curve does not exist. Thus, only pooling equilibria can exist. Because the choice of the high effort level is socially efficient, here we focus on pooling equilibria where both types exert effort. These equilibria involve cross-subsidization across types and Paretodominate any other equilibrium. Through the mispricing of equity at individual level, the B-type receives the subsidy necessary to induce him to work.

That is, in the presence of both adverse selection and (effort) moral hazard, in addition to conveying information, debt and equity play a second role. That of incentivizing the more prone to shirking type. This double role stems from the interaction between adverse selection and moral hazard and provides an explanation for the issue of combinations of debt and equity even if the issue of equity implies an adverse selection cost. What is more, in contrast with the pure adverse selection case, the cross-subsidization is socially beneficial. It converts negative into positive NPV projects and improves social welfare.

Proposition 4. Suppose that $\pi_{C} X_{G}-I>\pi_{C} c, \quad \pi_{C} X_{B}-I<\pi_{C} c \quad$ and $I / \pi_{C} X_{G}<1-c / X_{B}$. Then if $\lambda>\bar{\lambda}_{1}$ there exists a unique pooling (funding) equilibrium where both types choose the socially efficient high effort level and obtain funds by issuing a combination of debt and equity (See Figure 3).

where $\bar{\lambda}_{1} \equiv \frac{I-\pi_{C}\left(X_{B}-c\right)}{\pi_{C}\left(X_{G}-X_{B}\right)\left(1-c / X_{B}\right)}$

The equilibrium contract, $A=\left(\alpha^{*}, D^{*}\right)$, lies at the intersection of $I C F_{B}$ and $P Z P_{H}$ with $\alpha^{*}$ and $D^{*}$ given by:

$$
\begin{aligned}
& \alpha^{*}=\frac{I-\pi_{C}\left(X_{B}-c\right)}{\lambda \pi_{C}\left(X_{G}-X_{B}\right)} \\
& D^{*}=X_{B}-c /\left(1-\alpha^{*}\right)
\end{aligned}
$$


Proof: We test whether the contract at $A$ is an equilibrium by considering deviations. ${ }^{23}$ Offers below $Z P_{G}$ are clearly loss-making. Any offer in the area between $u_{G}^{A}$ (the G-type indifference curve through the equilibrium contract) and $Z P_{G}$ to the left of $I C F_{B}$ is going to be taken by both types and so is unprofitable. Thus, we only need to consider the following two deviations: i) Suppose that a financier deviates by offering a contract, say $A^{\prime}$, in the area between $u_{G}^{A}$ and $Z P_{G}$ to the right of $I C F_{B}$. Given that contract $A$ is still offered, the deviant contract, contract $A^{\prime}$, will reasonably attract only the G-type. This, in turn, implies that contract A is taken only by the B-type and so it becomes loss-making. As a result, at Stage 3, any application for that contract will be rejected. Anticipating that, the B-type will also choose $A^{\prime}$, at Stage 2, and hence $A^{\prime}$ becomes also loss-making (since to the right of $I C F_{B}, P Z P_{H}$ does not exist, and $P Z P_{L}$ lies to the right of $u_{G}^{A}$ ). Therefore, there is no profitable deviation to the right of $A$. ii) Consider now a financier who deviates by offering a contract, say $A^{\prime \prime}$, in the area between $I C F_{B}$ and $u_{G}^{A}$ to the left of (above) $A$. Given that contract $A$ is still offered, contract $A^{\prime \prime}$ will reasonably attract only the B-type and so is loss-making. Thus, any application for contract $A^{\prime \prime}$ will be rejected at stage 3. Actually, anticipating the rejection of that application at Stage 3, no B-type would make it at Stage 2. Therefore, the pooling equilibrium at $A$ is the unique equilibrium where funds are provided. ${ }^{24}$ Q.E.D.

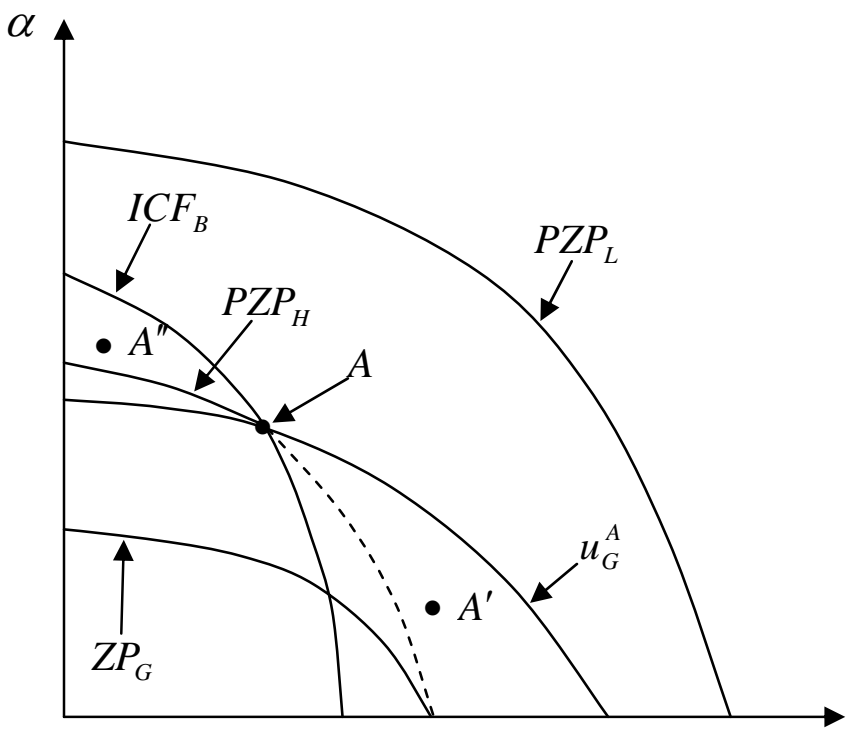

${ }^{23}$ In the Appendix, we also provide mathematical proofs for our results.

\footnotetext{
${ }^{24}$ It should be noted that uniqueness follows from the application of the "intuitive criterion". All contracts along (the relevant part of) $\mathrm{PZP}_{H}$ correspond to pooling perfect Bayesian equilibria under abritrary out-ofequilibrium beliefs. However, contract A is the only one that survives the "intuitive criterion" (Cho and Kreps, 1987).
} 
Figure 3. Pooling equilibrium where both debt and (mispriced) equity are issued.

The pooling equilibrium at $A$ reflects a trade-off between information revelation and effort incentives. The securities issued by the G- and B-type are priced as a pool. Although, because of perfect competition, debt and equity are fairly priced collectively, at individual level equity issued by the G-type is underpriced and that issued by the Btype overpriced. Not surprisingly, it is precisely this mispricing that provides the B-type with the subsidy necessary to induce him to exert effort. Hence, given that the singlecrossing condition is satisfied, the G-type has an incentive to deviate by choosing a contract involving more debt and less equity than the equilibrium contract. By doing so, he can credibly signal his type, reduce the cross-subsidization and increase his expected return.

However, his attempt will be fruitless. If the G-type chooses such a contract, the equilibrium contract becomes loss-making for the financiers and so any application for that will be rejected. As a result, the B-type will always mimic the G-type preventing him from revealing his type and obtaining funds in better terms. What is more, the deviant contract gives the B-type less subsidy and so destroys his effort incentives. The B-type shirks and the collective expected return falls significantly. A financier who offers a contract involving less equity than the equilibrium contract can break even only if he asks for a considerably greater face value of debt (higher interest rate on debt). But neither type prefers such a deviant contract to the equilibrium contract. Hence, no financier has an incentive to offer a contract involving less equity than the equilibrium contract and so the G-type stays in equilibrium and provides the B-type with just enough subsidy in order to induce him to work.

Loosely speaking, the G-type accepts to issue some equity and induce the B-type to exert effort because the increase in his net expected return (due to the lower interest rate he pays on debt) more than offsets the cost of the incremental subsidy (the adverse selection cost of issuing equity). That is, the G-type is better off in the pooling equilibrium of Proposition 4 where both debt and equity are issued and both types exert effort than in a pooling equilibrium where only debt is issued and so the B-type shirks (point $\mathrm{M}$ in Figure 3). ${ }^{25}$

Moreover, the role of debt and equity as communication devices implies that no financier can make a profit by offering a contract involving more equity (subsidy) and less debt than the equilibrium contract. Given that the equilibrium contract is still offered, the deviant contract will not be taken by any entrepreneur at Stage 2. If an entrepreneur chooses this contract, the financier will infer that he is a B-type. As a result, the deviant contract is loss-making and any application for that will be rejected at Stage 3. Anticipating that, no entrepreneur will apply for it at Stage 2.

\footnotetext{
${ }^{25}$ Notice that in the pooling equilibrium of Proposition 4 the G-type is worse off compared to the case where types are observable and he obtains funds at fair terms. However, social welfare exceeds that under full information about types (see also the discussion in Subsection 5.2.2).
} 
That is, the existence of the socially efficient pooling equilibrium relies on two factors: i) the endogenous (discrete) ${ }^{26}$ choice of the effort level and ii) the three-stage game structure that allows for an (interior) pooling perfect-Bayesian equilibrium even if cross-subsidization across types takes place and the single-crossing condition is met. ${ }^{27}$ Due to the presence of the third stage agents behave less myopically than in a two-stage screening game and so the non-existence problem is resolved.

If it exists, the pooling equilibrium of Proposition 4 has several interesting implications: First, it provides an explanation of why good firms issue both debt and underpriced equity even though the bankruptcy and other agency costs associated with debt are zero. Second, in contrast with the pure adverse selection case, the crosssubsidization is socially beneficial. It converts a negative into a positive NPV project and improves social welfare. Third, it has implications for empirical testing.

\subsubsection{Implications for the Issue of Securities}

To fix ideas, let us compare the adverse selection cum moral hazard case with the pure adverse selection and pure moral hazard cases. Under pure adverse selection, the securities issued are only used to convey socially costless information about the type of the project. Therefore, firms issue combinations of debt and equity only if both securities are fairly priced not only collectively but also individually. Pooling equilibria involving cross-subsidization can exist only if the less valuable for the subsidizer security (debt) is issued (corner solution). In this case, there is no channel through which the cross-subsidy can have positive effects for the subsidizer. As a result, the subsidizer maximizes his return by minimizing the subsidy he provides the other type.

In contrast, in the presence of effort moral hazard, if the subsidizer cannot reveal his type, it may be in his interest to incur the adverse selection cost of issuing some of the more valuable for him security. By doing so, he provides the more prone to shirking type with the subsidy necessary to induce him to work and so the collective expected return rises. If the resulting increase in his expected return exceeds this adverse selection cost, the subsidizer's welfare improves. For example, in Proposition 4 the benefit (due to the lower interest rate he pays on debt) for the G-type from accepting to issue some equity and inducing the B-type to exert effort exceeds the underpricing of his equity (the adverse selection cost associated with the equity issue). ${ }^{28}$

\footnotetext{
${ }^{26}$ We conjecture that, under certain restrictions on the probability and cost functions, this pooling equilibrium exists even if the effort level is a continuous variable.

${ }^{27}$ In a two-stage signalling game, such a pooling equilibrium cannot exist. Behaving myopically, the Gtype tries to reveal his type by issuing more debt and less equity. However, the B-type always mimics and, more importantly, his effort incentives are destroyed. Therefore, there can exist either pooling equilibria where only debt is issued (corner solution) and the G-type works whereas the B-type shirks or pooling equilibria where both types shirk and so no funds are provided. In either case, the resulting pooling equilibria are Pareto-inferior to that of Proposition 4.

${ }^{28}$ Notice that, although the pooling equilibrium of Proposition 4 involves cross-subsidization across types of entrepreneurs, it does not involve cross-subsidization across debt and equity. Once the equilibrium is determined, the value of these two contracts can be calculated independently and so debt and equity could be traded separately in a secondary market. In fact, the same equilibrium obtains even if instead of one financier offering both debt and equity, the financiers specialize in one of the two contracts and debt and equity markets are perfectly competitive (see Appendix for a proof).
} 
In the pure moral hazard case, the financiers observe the type of each individual entrepreneur. As a result, each type is offered contracts along the corresponding zeroprofit curve, provided it exists. In the context of our simple model, the mode of financing is irrelevant. ${ }^{29}$ All combinations of debt and equity along the existing zero-profit curve are offered and are equally preferred by the corresponding type.

\subsubsection{Implications for Investment and Social Welfare}

Under the conditions in Proposition 4, if types were observable only the G-type would receive financing. If the B-type receives funds at fair terms he shirks and so his project NPV is negative. Moreover, financiers have no incentive to transfer resources from the G-type to the B-type to induce the latter to exert effort. Thus, no rational financier would be willing to offer the B-type the required for the investment funds and so the B-type project would not be undertaken. That is, under full information about types a potentially positive NPV investment opportunity is forgone. Furthermore, because when the B-type works his project NPV exceeds the cost of effort, the social welfare also worsens.

These results are in sharp contrast with the pure adverse selection case. In Myers and Majluf (1984) adverse selection leads firms to forego positive NPV projects whereas in de Meza and Webb (1987) it encourages firms to undertake negative NPV projects. Hence, in either case social welfare is lower than under full information about types. The key to this difference is that in the presence of (effort) moral hazard the crosssubsidization taking place in a pooling equilibrium relaxes this additional constraint and so it can be beneficial. In contrast, given risk neutrality, under pure adverse selection there is no channel through which the cross-subsidy can have positive effects but it may have negative consequences.

\subsubsection{Empirical Implications}

This pooling equilibrium also has implications for empirical testing: i) From Eq. (5) it is clear that the higher the proportion of low-profitability firms (the lower $\lambda$ ), the higher (lower) the fraction of funds raised through equity (debt). Intuitively, as the proportion of the G-type falls, the fraction of equity needed to provide the B-type with the subsidy necessary to induce him to work increases. This prediction is consistent with the findings in Fama and French (2005). ii) Because debt issued by both types is equally valuable while the G-type equity is more valuable, ex post, good firms have lower debt-equity ratios (market values). This negative relation between leverage and profitability has been documented by several empirical studies (e.g., Titman and Wessels (1988), Rajan and Zingales (1995) and Fama and French (2002)).

\section{The Role of Warrants}

\footnotetext{
${ }^{29}$ This result is due to the assumption that in case of failure the project yields zero regardless of its type. If instead we assume that in case of failure the return is strictly positive then debt becomes the optimal contract (Innes (1990)). All the main results go through under the latter assumption. However, the zeroreturn assumption simplifies considerably the analysis without losing any insight.
} 
So far, the available financial instruments have been debt and equity. The discussion of the previous section illustrated the roles of these two financial contracts as separation devices and means of incentivizing the more prone to shirking type. In this section, we introduce financing instruments with option features. More specifically, the entrepreneurs can borrow the required amount I by issuing a debt-warrant combination.

The warrant gives its holder the right to purchase a prespecified proportion of the firm's equity, $\eta$, at an agreed price K (exercise price). The proceeds from the exercise of the option, $\mathrm{K}$, are distributed as dividends to the shareholders. Therefore, a warrant holder will exercise if

$$
\eta_{i}\left(X_{i}-D_{i}+K_{i}\right) \geq K_{i}, \quad K_{i} \geq 0, \quad i=G, B
$$

This can be rewritten as

$$
K_{i} \leq \frac{\eta_{i}}{1-\eta_{i}}\left(X_{i}-D_{i}\right), \quad i=G, B
$$

So, given risk neutrality and limited liability, the entrepreneurs seek to maximize:

$$
U_{i}\left(X_{i}, \eta_{i}, D_{i}, C_{i}, K_{i}\right)=\pi\left(C_{i}\right) \operatorname{Min}\left\{\left(1-\eta_{i}\right)\left(X_{i}-D_{i}+K_{i}\right), \operatorname{Max}\left[\left(X_{i}-D_{i}\right), 0\right]\right\}
$$

where $U_{i}$ is the expected utility of an entrepreneur of type $\mathrm{i}$ when choosing the contract $\Xi_{i}=\left(\eta_{i}, D_{i}, K_{i}\right)$. Similarly, given limited liability, the expected profit of a financier offering the contract $\Xi_{i}=\left(\eta_{i}, D_{i}, K_{i}\right)$ is given by:

$$
P_{F}=\pi\left(C_{i}\right) \operatorname{Max}\left\{\eta_{i}\left(X_{i}-D_{i}+K_{i}\right)-K_{i}+D_{i}, \operatorname{Min}\left(X_{i}, D_{i}\right)\right\}-I
$$

To make the analysis interesting, we assume that the exercise price is set such that, in case of success, the option is exercised regardless of the type of the project. That is, the exercise price is given by:

$$
K_{i}=\frac{\eta_{i}}{1-\eta_{i}}\left(1-\psi_{i}\right)\left(X_{B}-D_{i}\right) \quad \text { where } \psi_{i} \in[0,1], \quad i=G, B
$$

Eq. (10) is a sufficient condition for the warrants issued by both types to be exercised in case of success. ${ }^{30}$ Furthermore, without loss of generality, we assume $\psi_{G}=\psi_{B}=\psi \in[0,1] .{ }^{31}$ Basically, this assumption reduces the choice variables from three

\footnotetext{
${ }^{30}$ This condition is imposed for simplicity. All results go through if instead of $X_{B}$ in Eq. (10) we had $X_{G}$ or even if we specified a different function for the exercise of the warrant issued by each type. However, these modifications would complicate the analysis without adding any insight.

${ }^{31}$ A combination of debt and equity is a special case of a debt-warrant combination that obtains for $\psi_{G}=\psi_{B}=1$.
} 
$(\eta, D, K)$ to two $(\eta, D)$. The choice of $\eta$ and $D$ completely determines $K$. By doing so, we considerably simplify the analysis without losing any insight. ${ }^{32}$ Using Eq. (10) and the assumption about $\psi$, the utility and profit functions simplify respectively to:

$$
\begin{gathered}
U_{i}\left(X_{i}, \eta_{i}, D_{i}, C_{i}, K_{i}\right)=\pi\left(C_{i}\right)\left[\left(1-\eta_{i}\right)\left(X_{i}-D_{i}\right)+\eta_{i}(1-\psi)\left(X_{B}-D_{i}\right)\right] \\
P_{F}=\pi\left(C_{i}\right)\left\{\eta_{i}\left[\left(X_{i}-D_{i}\right)-(1-\psi)\left(X_{B}-D_{i}\right)\right]+D_{i}\right\}-I
\end{gathered}
$$

\subsection{Indifference Curves and Effort Incentive Constraints}

A given contract $(\eta, D)$ will induce the high effort level if

$$
(1-\eta)\left(X_{i}-D+K\right) \geq c
$$

So, the equations of the effort incentive frontiers $I C F_{B}$ and $I C F_{G}$ are given respectively by:

$$
\begin{gathered}
(1-\psi \eta)\left(X_{B}-D\right)=c \\
(1-\psi \eta)\left(X_{G}-D\right)-\eta(1-\psi)\left(X_{G}-X_{B}\right)=c
\end{gathered}
$$

The family of indifference curves of type i can be derived from Eq. (11). The indifference curves have the same slope as the corresponding effort incentive frontiers. As a result, no indifference curve of type i crosses $I C F_{i}$ and therefore the indifference curves do not exhibit kinks in the $(\eta, D)$ space. One of the indifference curves coincides with the corresponding ICF.

Lemma 6. In the $(\eta, D)$ space:

a) $I C F_{G}$ and $I C F_{B}$ are downward sloping and strictly concave. At any $(\eta, D)$ pair, $I C F_{G}$ is flatter than $I C F_{B}$.

b) For any $\psi \leq 1-c / X_{B}, I C F_{G}$ and $I C F_{B}$ intersect at some $(\eta=1, D \geq 0)$.

c) The indifference curves of the $\mathrm{G}$ - and B-type have the same slope as the corresponding effort incentive frontiers.

Proof: See the Appendix.

\footnotetext{
${ }^{32}$ No more than two choice variables are necessary for our purposes. Clearly, all the results go through if we increase their number to three by allowing for $\psi_{G} \neq \psi_{B}$.
} 
Notice that now $I C F_{G}$ and $I C F_{B}$ can intersect at admissible values of the choice variables $(\eta, D)$ although when the financial instruments available are debt and equity $I C F_{B}$ lies entirely below $I C F_{G}$. Intuitively, since $X_{G}>X_{B}$, at any given $(\eta, D)$ pair, a given fall in $\psi$ (increase in the exercise price) implies that the project's return constitutes a smaller proportion of the total payment to the warrantholder if the warrant is issued by the B-type. That is, as the exercise price rises, the warrant value falls proportionately faster for the B-type and so the B-type is willing to increase faster the proportion of equity, $\eta$, offered to the financier than the G-type while still exerting effort. ${ }^{33}$ As a result, for $\psi$ sufficiently low $\left(\psi \leq 1-c / X_{B}\right), I C F_{G}$ and $I C F_{B}$ intersect at some positive face value of debt, $D$, even if this is not possible when we restrict ourselves to debt and equity or convertible debt. ${ }^{34}$

\subsection{Zero-profit Curves}

The expected profit of a financier offering a contract $(\eta, D)$ is given by Eq. (12). Given Assumption 1, the zero-profit curve corresponding to the i-type ( $\left.Z P_{i}\right)$ exists only if the itype exerts effort when he receives funds at fair terms. ${ }^{35}$ Conditional on the choice of the high effort level there exist three zero-profit curves: that corresponding to the G-type $\left(Z P_{G}\right)$, to the B-type $\left(Z P_{B}\right)$, and the pooling zero-profit curve $\left(P Z P_{H}\right)$. The equations of the zero-profit curves $Z P_{B}$ and $Z P_{G}$ are respectively:

$$
\begin{gathered}
\pi_{C}\left[\eta \psi\left(X_{B}-D\right)+D\right]=I \\
\pi_{C}\left\{\eta\left[\psi\left(X_{B}-D\right)+\left(X_{G}-X_{B}\right)\right]+D\right\}=I
\end{gathered}
$$

The key properties of the zero-profit curves and their relationship with the corresponding indifference curves and effort incentive frontiers are similar to those under debt and equity (see Lemma 3). Since $X_{G}>X_{B}$, given the effort level, the warrants issued by the G-type are more valuable than those of the B-type whereas debt issued by both types is equally valuable. As a result, in the pure adverse selection case the equilibrium is also similar to that prevailing when the financing instruments are debt and equity. That is, the G-type always issues debt whereas the B-type issues either just debt or any combination of debt and warrants.

However, because the introduction of warrants affects asymmetrically the effort incentive constraints of the two types, their use will have significant effects on the equilibrium that obtains when adverse selection and moral hazard interact.

\footnotetext{
${ }^{33}$ Diagrammatically, in the $(\eta, D)$ space, as $\psi$ falls $I C F_{B}$ becomes steeper faster than $I C F_{G}$.

${ }^{34}$ Details about the case of convertible debt are available from the author upon request. For an intuitive explanation of why, in our model, convertible debt does not improve on a debt-equity combination see Footnote 6.

${ }^{35}$ By Assumption 1, the NPV of both types of projects is strictly positive if the high effort level is chosen whereas it is strictly negative if shirking is chosen.
} 


\subsection{The Adverse Selection cum Moral Hazard Case}

In this subsection, we show that a debt-warrant combination allows for the existence of the socially efficient pooling equilibrium under weaker restrictions on parameter values than a debt-equity combination.

Proposition 5. Suppose $\pi_{C} X_{G}-I>\pi_{C} c, \pi_{C} X_{B}-I<\pi_{C} c$. Then for any $\psi \leq 1-c / X_{B}$ and $\lambda \geq \bar{\lambda}_{2}$, then there exists a unique pooling (funding) equilibrium where both types exert effort and obtain funds by issuing a debt-warrant combination (see Panel $B$ in Figure 4).

where $\quad \bar{\lambda}_{2} \equiv \frac{I-\pi_{C}\left(X_{B}-c\right)}{\pi_{C}\left(X_{G}-X_{B}\right)}<\bar{\lambda}_{1}$

The equilibrium contract, $A=\left(\eta^{*}, D^{*}\right)$, lies at the intersection of $I C F_{B}$ and $P Z P_{H}$ with $\eta^{*}$ and $D^{*}$ given by:

$$
\begin{gathered}
\eta^{*}=\frac{I-\pi_{C}\left(X_{B}-c\right)}{\lambda \pi_{C}\left(X_{G}-X_{B}\right)} \\
D^{*}=X_{B}-c /\left(1-\psi \eta^{*}\right)<K^{*}
\end{gathered}
$$

Proof: Similar to Proposition 4 (see the Appendix).

To illustrate the role of warrants, we graphically compare the case where the firms can issue a debt-equity combination with the case they issue a debt-warrant combination (see Panels A and B in Figure 4). By Lemma 1, if firms can only issue debt and equity, under this distributional assumption, $I C F_{B}$ lies entirely below $I C F_{G}$ (see also Figure 1). Also, because the G-type equity is more valuable, as his proportion in the population of entrepreneurs, $\lambda$, decreases the pooling zero-profit curve $P Z P_{H}$ becomes steeper and intersects $I C F_{B}$ at points corresponding to a higher proportion of equity. A necessary condition for the existence of the efficient pooling equilibrium is that $P Z P_{H}$ both intersects $I C F_{B}$ and lies below $I C F_{G}\left(P Z P_{H}\right.$ is constructed conditional on both types exerting effort). If $\lambda$ falls below $\bar{\lambda}_{1}, P Z P_{H}$ lies entirely above $I C F_{B}$ and so it is not relevant (see Panel A in Figure 4). As a result, the socially efficient pooling equilibrium collapses although the G-type would exert effort even if a higher proportion of equity was issued.

Because the warrant value falls with the exercise price proportionately faster for the Btype, as the warrant exercise price rises both $I C F_{B}$ and $P Z P_{H}$ become steeper but $I C F_{B}$ becomes so at a higher rate. As a result, for a sufficiently high exercise price, $I C F_{B}$ and 
$\mathrm{PZP}_{H}$ meet again and the existence of the socially efficient pooling equilibrium is restored (see Panel B in Figure 4). That is, a debt-warrant combination allows for the existence of the efficient pooling equilibrium even if it collapses when firms can issue only debt and equity (and/or convertible debt).

Intuitively, in this case, if firms can only issue debt and equity, at any given debt level, the proportion of equity issued consistent with exerting effort is strictly lower for the Btype. That is, the pooling equilibrium where both types exert effort may collapse although the G-type would have exerted effort even if a higher proportion of equity was issued (more subsidy was given to the B-type). In absolute terms, the value of warrants issued by either type falls with the exercise price by the same amount. ${ }^{36}$ However, because in case of success $X_{G}>X_{B}$, the warrant value falls with the exercise price (proportionately) faster for the B-type. As a result, the B-type is willing to increase the proportion of equity offered to the financier faster than the G-type while still exerting effort. That is, the warrant payoff function between $X_{G}$ and $X_{B}$ can be steeper than the equity payoff function without violating the B-type effort incentive constraint.

This implies that the difference between the total value of the warrants issued by the G- and B-type can exceed the corresponding difference of equity values consistent with both types working. This larger difference allows for the provision of the subsidy necessary to induce the B-type to work when the proportion of the G-type is so low that the socially efficient pooling equilibrium breaks if a debt-equity combination is used.

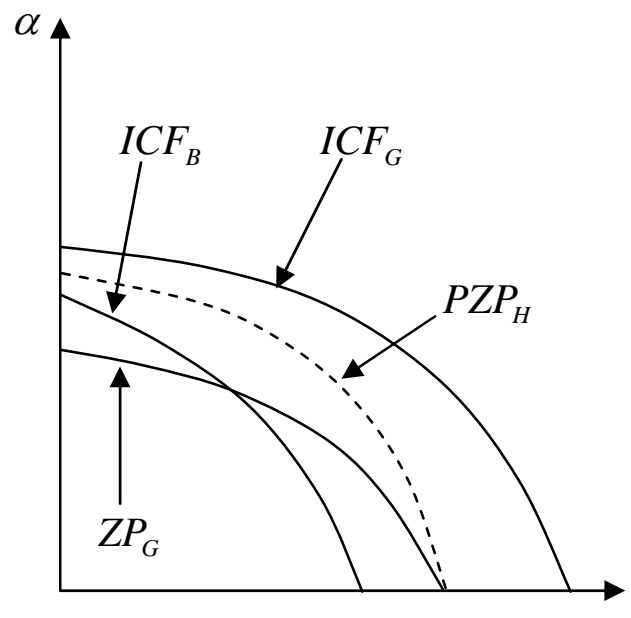

0 Panel A: Debt-Equity

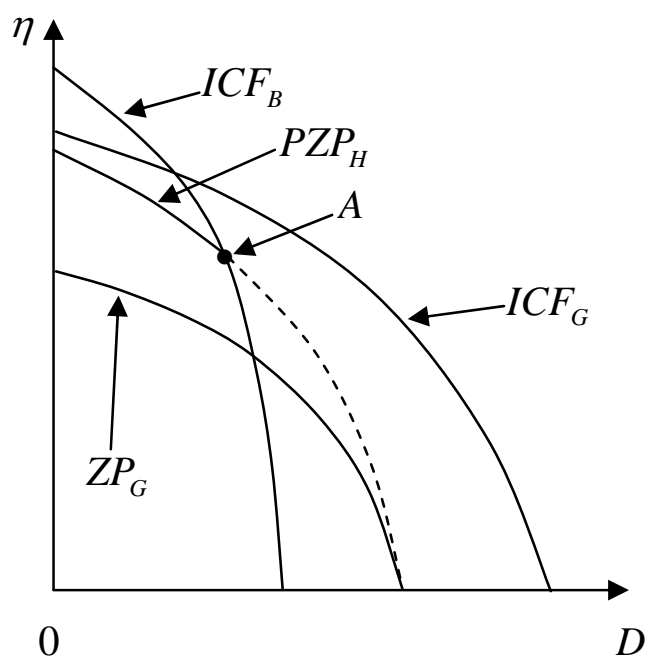

Panel B: Debt-Warrant

Figure 4. The role of warrants.

\footnotetext{
${ }^{36}$ That is, in absolute terms, the difference in the value of the warrants issued by the G-type and the B-type (regardless of the exercise price) is the same as the difference in the value of equity issued by the two types (given the face value of debt).
} 
The mechanism at work here relies on the fact that the warrant exercise price can be greater than the face value of debt. Given the face value of debt, by choosing a sufficiently high exercise price, we can create a security with a sufficiently steep payoff function which exploits the difference between the returns of the two types of projects and satisfies the B-type's effort incentive constraint under weaker conditions than if warrants were not available. In other words, through the appropriate choice of their exercise price, warrants allow for the implementation of the socially efficient outcome even if this is not possible when we restrict ourselves to debt, equity and/or convertible debt. $^{37}$ This mechanism provides a rationale for their use.

\section{Optimal Financial Contracts under Adverse Selection and Moral Hazard}

If both the type and the actions of the entrepreneurs were observable (and verifiable), both types would exert effort if they were offered funds at fair terms. As a result, the net social surplus (social welfare) would be maximized (first best). However, if the choice of the effort level is not observable and one of the two types (the B-type) shirks if he receives funds at fair terms, the implementation of the socially efficient outcome requires cross-subsidization across types. In this section, we address the following question: Can competitive financial markets implement the socially efficient outcome under the same conditions as a benevolent central authority (social planner) who aims at maximizing social welfare?

Competitive financiers have no incentive to transfer resources from the G-type to the B-type to induce the latter to exert effort. Therefore, if types are observable or can be credibly revealed, they offer funds only to the G-type and so competitive markets cannot maximize social welfare. In a competitive environment, the implementation of the socially efficient outcome can be achieved only in a pooling equilibrium where the required cross-subsidization takes place through the mispricing of the G-type's more valuable security (equity). We begin by characterizing the social planner's solution (the optimal contract) under adverse selection and effort moral hazard.

\subsection{The Social Planner's Solution: The Optimal Contract}

The social planner's objective is to induce both types to exert effort whenever feasible. Hence, the social planner will offer the B-type the required subsidy even if he can distinguish the two types, provided the G-type effort incentive constraint is not violated. Since the returns of the two types in case of success are different, observable and verifiable, the social planner can ex post distinguish the two types and promise to offer them funds at fair terms. Moreover, he can commit to making direct lump-sum transfers, $\tau$, from the G-type to the B-type so that the B-type effort incentive constraint and the social planner feasibility constraint are just binding, and the G-type effort incentive constraint is not violated. Mathematically,

\footnotetext{
${ }^{37}$ In our model, convertible debt does not improve on a debt-equity combination (see Footnote 6).
} 


$$
\begin{gathered}
\left(X_{B}-I / \pi_{C}-\tau_{B}\right)=c \\
\left(X_{G}-I / \pi_{C}-\tau_{G}\right) \geq C \\
\lambda \pi_{C} \tau_{G}+(1-\lambda) \pi_{C} \tau_{B}=0
\end{gathered}
$$

Solving (20) and (21) for $\tau_{B}$ and $\tau_{G}$ respectively and substituting into (22), we obtain:

$$
\lambda \geq \frac{I-\pi_{C}\left(X_{B}-c\right)}{\pi_{C}\left(X_{G}-X_{B}\right)} \equiv \lambda^{S P}=\bar{\lambda}_{2}
$$

Where $\lambda^{S P}$ is the minimum proportion of the G-type (subsidizer) in the population of entrepreneurs consistent with both types exerting effort. In fact, it is the only restriction on the parameter values the social planner faces in his attempt to implement the socially efficient outcome. That is, the optimal contract involves the resolution of the adverse selection problem and lump-sum transfers.

\subsection{Implementing the Optimal Contract with Debt and Warrants}

Now that we have characterized the optimal contract, we examine its implementation as a competitive equilibrium using financial instruments observed in the real world. By Proposition 5, we know that, for any $\lambda \geq \bar{\lambda}_{2}=\lambda^{S P}$ there exists a pooling equilibrium where both types exert effort and receive funds by issuing a debt-warrant combination. That is, the only restriction on parameter values required for the existence of the socially efficient pooling equilibrium is that the social planner also faces. Therefore, debt coupled with a warrant can implement the optimal contract as a competitive equilibrium.

This result relies on two factors: First, on the fact that warrants allow for the intersection of the two effort incentive frontiers at some admissible value of the two choice variables, the proportion of equity, $\eta$, and the face value of debt, $D$. This, in turn, implies that the socially efficient pooling equilibrium exists until the proportion of the Gtype becomes so low that it is impossible to satisfy both effort incentive constraints. This is exactly the constraint the social planner faces. Second, on the fact that the socially efficient pooling equilibrium Pareto-dominates any other equilibrium even if both effort incentive constraints are just binding. In other words, the G-type's benefit from inducing the B-type to exert effort through the mispricing of warrants more than offsets the incremental subsidy (relative to the all-debt equilibrium where the B-type shirks) even if the total subsidy is so high that the G-type effort incentive constraint is just binding. ${ }^{38}$

\footnotetext{
${ }^{38}$ See also the Proofs of Propositions 4 and 5 in the Appendix.
} 


\section{Conclusion}

In this paper, we consider project financing under adverse selection and (effort) moral hazard. Several interesting results are obtained. First, we provide an explanation of why good firms issue underpriced equity even though the bankruptcy and other agency costs associated with debt are zero. This mispricing provides bad entrepreneurs with the subsidy necessary to induce them to exert effort. The resulting increase in the aggregate expected return leads to a fall in the interest rate on debt (gain) which is greater than the underpricing of equity. That is, good firms accept to incur the adverse selection cost of issuing equity because this cost is more than offset by the benefit from relaxing the moral hazard constraint. Second, we showed that, in the presence of moral hazard, this mispricing may result in the conversion of a negative into a positive NPV project and an improvement in the aggregate expected returns and social welfare. Third, we provide a rationale for the necessity of the use of warrants. Warrants allow for the implementation of the socially efficient outcome even if this is not possible when only debt, equity and/or convertible debt are available.

Finally, our results have also some implications for empirical testing: i) The higher the proportion of low-profitability (B-type) firms, the higher the fraction of funds raised through equity. This prediction is consistent with the findings in Fama and French (2005). ii) As the proportion of low-profitability firms rises, warrants should become a more important financing instrument. To the best of our knowledge, this prediction has not been tested yet. iii) Because the G-type equity is more valuable, ex post, good firms have lower debt-equity ratios (market values). This negative relation between leverage and profitability has been documented by several empirical studies (e.g., Titman and Wessels (1988), Rajan and Zingales (1995) and Fama and French (2002)). 


\section{Appendix}

Proof of Lemma 1: a) By totally differentiating Eq. (3), we obtain:

$$
-\left(X_{i}-D\right) d \alpha-(1-\alpha) d D=0 \Rightarrow \quad\left(\frac{d \alpha}{d D}\right)_{I C F_{i}}=-\frac{1-\alpha}{X_{i}-D}<0
$$

Taking into account that $I C F_{i}$ implicitly defines $\alpha$ as a function of $D$, we obtain:

$$
\left(\frac{d^{2} \alpha}{d D^{2}}\right)_{I C F_{i}}=-\frac{1-\alpha}{\left(X_{i}-D\right)^{2}}+\frac{\frac{d \alpha}{d D}}{X_{i}-D}=-\frac{2(1-\alpha)}{\left(X_{i}-D\right)^{2}}<0
$$

Hence, $I C F_{i}$ is downward sloping and strictly concave. Also, since $X_{G}>X_{B}, I C F_{G}$ is flatter than $I C F_{B}$.

b) The effort incentive frontiers of the G- and B-type are respectively:

$$
\begin{aligned}
& (1-\alpha)\left(X_{G}-D\right)=c \\
& (1-\alpha)\left(X_{B}-D\right)=c
\end{aligned}
$$

Because $X_{G}>X_{B}$, the intersection of $I C F_{B}$ with the vertical axis lies below that of $I C F_{G}$. Also, at any $0 \leq \alpha \leq 1, I C F_{B}$ is steeper than $I C F_{G}$. Therefore, $I C F_{B}$ lies entirely below $I C F_{G}$ in the $(\alpha, D)$ space. That is, $I C_{B} \subset I C_{G}$.

c) $I C F_{i}$ meets the vertical axis at $\alpha_{i}=1-c / X_{i}$ and the horizontal axis at $D_{i}=X_{i}-c$. By Assumption 1, $X_{i}>c$ and $1>c / X_{i}$. Also, by Part (a) of this Lemma, ICF $F_{i}$ is downward sloping and strictly concave. Therefore, $I C_{i}$ cannot be empty (See Figure 1). Q.E.D.

Proof of Lemma 2: a) For any $0 \leq \alpha \leq 1,0 \leq D \leq X_{i}$, Eq. (1) becomes:

$$
U_{i}=\pi\left(C_{i}\right)(1-\alpha)\left(X_{i}-D\right), \quad i=G, B
$$

Differentiating (A3), we obtain: 


$$
\left(\frac{d \alpha}{d D}\right)_{u_{i}=\bar{u}}=-\frac{1-\alpha}{X_{i}-D} \leq 0
$$

$u_{i}=u$ implicitly defines $\alpha$ as a function of $D$ and so:

$$
\left(\frac{d^{2} \alpha}{d D^{2}}\right)_{u_{i}=\bar{u}}=-\frac{2(1-\alpha)}{\left(X_{i}-D\right)^{2}} \leq 0
$$

Hence, the indifference curves of both the G- and the B-type are downward sloping and concave.

b) Since $X_{G}>X_{B}$, at any $(\alpha, D)$ pair, $u_{G}$ is flatter than $u_{B}$ and hence they cross only once. Q.E.D.

Proof of Lemma 3: a) The equations for $Z P_{i}$ and $P Z P_{H}$ are respectively:

$$
\begin{gathered}
\pi_{C}\left[\alpha\left(X_{i}-D\right)+D\right]=I, \quad i=G, B \\
\lambda \pi_{C}\left[\alpha\left(X_{G}-D\right)+D\right]+(1-\lambda) \pi_{C}\left[\alpha\left(X_{B}-D\right)+D\right]=I
\end{gathered}
$$

Differentiating (A4) and (A5) we obtain the slopes of $Z P_{i}$ and $P Z P_{H}$ respectively.

$$
\begin{gathered}
\left(\frac{d \alpha}{d D}\right)_{Z P_{i}}=-\frac{1-\alpha}{X_{i}-D}<0 \\
\left(\frac{d \alpha}{d D}\right)_{P Z P_{H}}=-\frac{(1-\alpha)}{\lambda\left(X_{G}-D\right)+(1-\lambda)\left(X_{B}-D\right)}<0
\end{gathered}
$$

b) Using (A4), (A5) and solving for $\alpha$ and $D$, we obtain the values of $\alpha$ and $D$ where $Z P_{G}$ and $Z P_{B}$ intersect in the $(\alpha, D)$ space.

$$
\hat{\alpha}=0, \quad \hat{D}=I / \pi_{C}
$$

Also, $Z P_{G}$ is flatter than $Z P_{B}$. Hence, for $\alpha>0 \quad Z P_{G}$ lies below $Z P_{B}$ in the $(\alpha, D)$ space.

Since $X_{G}>X_{B}$ and $0 \leq \lambda \leq 1$, it is obvious that at any given $(\alpha, D)$ pair, 


$$
\left|\left(\frac{d \alpha}{d D}\right)_{Z P_{B}}\right| \geq\left|\left(\frac{d \alpha}{d D}\right)_{P Z P_{H}}\right| \geq\left|\left(\frac{d \alpha}{d D}\right)_{Z P_{G}}\right|
$$

c) By Lemmas 1, 2, and 3

$$
\left(\frac{d \alpha}{d D}\right)_{I C F_{i}}=\left(\frac{d \alpha}{d D}\right)_{u_{i}=\bar{u}}=\left(\frac{d \alpha}{d D}\right)_{Z P_{i}}=-\frac{1-\alpha}{X_{i}-D}<0, \quad i=G, B
$$

Hence, $I C F_{i}, u_{i}, Z P_{i}(i=G, B)$ never intersect. Q.E.D.

Proof of Lemma 4: If $\pi_{C} X_{i}-I \geq \pi_{C} c$, then the intersection point of $Z P_{i}$ with the vertical axis, $\left(I / \pi_{C} X_{i}\right)$, lies (weakly) below that of $I C F_{i},\left(1-c / X_{i}\right)$. By Lemma 3, $Z P_{i}$ and $I C F_{i}$ never intersect (they may coincide). Therefore, $Z P_{i}$ belongs to $I C_{i}$ and hence it exists. Conversely, if $\pi_{C} X_{i}-I<\pi_{C} c$, then $Z P_{i}$ lies outside $I C_{i}$ and so it does not exist. In the latter case, if the i type obtains funds at fair terms, his effort incentive constraint is violated and so he opts for shirking contradicting the condition $\left(\pi^{i}=\pi_{C}^{i}\right)$ on which $Z P_{i}$ is constructed. Q.E.D.

Proof of Lemma 6: The equations of the effort incentive frontiers $I C F_{B}$ and $I C F_{G}$ are given respectively by:

$$
\begin{gathered}
(1-\psi \eta)\left(X_{B}-D\right)=c \\
(1-\psi \eta)\left(X_{G}-D\right)-\eta(1-\psi)\left(X_{G}-X_{B}\right)=c
\end{gathered}
$$

a) By totally differentiating (A8) and (A9), we obtain the slopes of $I C F_{B}$ and $I C F_{G}$ respectively (the equations are provided in the text). Since $X_{G}>X_{B}$, at any given $(\eta, D)$ pair, $I C F_{B}$ is steeper than $I C F_{G}$.

b) Solving (A8) and (A9) for $\eta$ and $D$, we obtain:

$$
\begin{aligned}
\bar{\eta}=1, \quad \bar{D} & =\frac{\left(X_{B}-c\right)\left[X_{G}-(1-\psi) X_{B}\right]-\psi\left(X_{G}-c\right) X_{B}}{(1-\psi)\left(X_{G}-X_{B}\right)} \\
\bar{D} \geq 0 & \Leftrightarrow \quad \psi \leq 1-c / X_{B} \equiv \bar{\psi}
\end{aligned}
$$


c) Setting the utility (Eq. (11) in the text) of an entrepreneur of type i equal to a constant and differentiating, we obtain the slopes of the indifference curves which are identical to the corresponding slopes of the effort incentive frontiers. Q.E.D.

Proof of Proposition 3: By Lemma 4, in this case, $I C F_{i}$ lies above $Z P_{i}, i=G, B$, and so we can proceed with the analysis ignoring the effort incentive constraints. Let $\left(A_{G}, A_{B}\right)$ be the equilibrium pair of contracts (in a pooling equilibrium $A_{G}=A_{B}=A$ ). We test whether the pair $\left(A_{G}, A_{B}\right)$ or $A$ is an equilibrium by considering deviations.

Clearly, offers below $Z P_{G}$ are unprofitable. Also, any offer along $Z P_{G}$ (to the left of point $A$ ) would attract both types and so is loss-making. Thus, there cannot exist a separating equilibrium where the G-type issues equity. We next show that there cannot exist a pooling equilibrium where equity is issued. If there exists a pooling equilibrium it must lie on the pooling zero-profit curve $\left(P Z P_{H}\right)$. Suppose that the pooling equilibrium contract is contract $\mathrm{N}$ that lies on $P Z P_{H}$ to the left of point $A$ (see Figure A1). Consider now the following deviation: A financier offers a contract just below $\mathrm{N}$ in the area between the indifference curve of the two types through $\mathrm{N}$. Given contract $\mathrm{N}$ is still offered, the deviant contract will reasonably attract only an G-type and so is profitable (since it lies above $Z P_{G}$ ). At the same time, contract $\mathrm{N}$ becomes loss-making and so any application for it would be rejected at Stage 3. Thus, contract $\mathrm{N}$ (any contract on $P Z P_{H}$ to the left of point $A$ ) cannot be a pooling equilibrium.

Consider now a financier who deviates by offering a contract in the area between $Z P_{G}$ and $Z P_{B}$. Given contract $A$ is still offered, at Stage 3 , the deviant financier will reasonably infer that his contract will be chosen by a B-type. As a result, the deviant contract is unprofitable (loss-making) and so any application for it will be rejected at Stage 3. Actually, anticipating the rejection of this application, no B-type would make it at Stage 2. Therefore, contract $A$ which involves both types issuing only debt is a pooling equilibrium (see Figure A1). Finally, any pair $\left(A_{G}, A_{B}\right)$, where $A_{G}=A$ and $A_{B}$

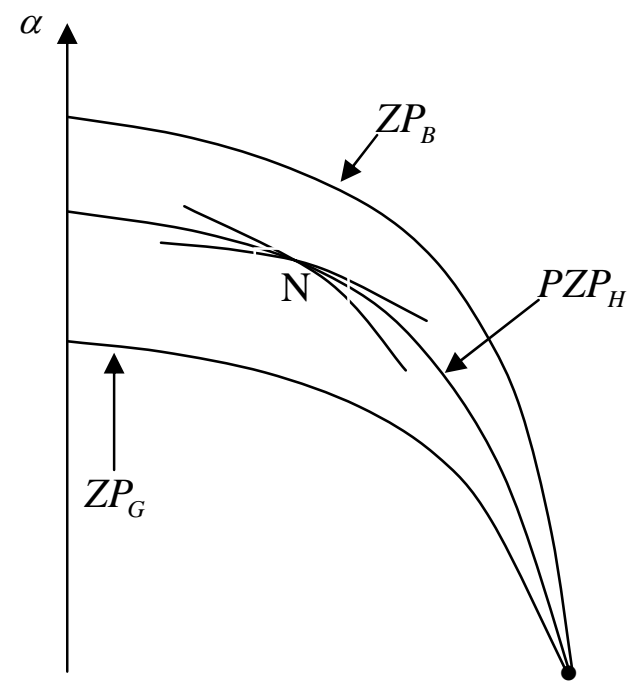


Figure A1. Equilibria under pure adverse selection.

lies on $Z P_{B}$ to the left of $A$, is a separating equilibrium. Because debt issued by both types at $A$ is fairly priced, the B-type is indifferent between issuing debt and any debtequity combination along $Z P_{B}$. Also, given contract $A$, the financiers are equally well off by offering any contract along $Z P_{B}$ because, given contract $A$, any such an offer is going to be taken only by the B-type. Thus, none of these separating pairs can be ruled out. $^{39}$ Q.E.D.

Proof of Proposition 4: The pooling equilibria described in this proposition exist if the following two conditions are satisfied: a) $P Z P_{H}$ belongs to the intersection of $I C_{B}$ and $I C_{G}$ for $\lambda \leq 1$ and $\mathrm{b}$ ) the G-type indifference curve through the equilibrium contract $A$, $u_{G}^{A}$, does not intersect $P Z P_{L}$ (see Figure 3).

a) In the debt-equity case, since $I C_{B} \subset I C_{G}$ the first condition is satisfied if $P Z P_{H}$ crosses $I C F_{B}$. Provided $Z P_{G}$ intersects $I C F_{B}\left(I / \pi_{C} X_{R}<1-c / X_{B}\right)$, by Figure 3 , it is clear that $P Z P_{H}$ crosses $I C F_{B}$ if the intersection point of $P Z P_{H}$ with the vertical axis lies below that of $I C F_{B}$. That is, if

$$
\begin{aligned}
& 1-\frac{c}{X_{B}}>\frac{I}{\pi_{C}\left(\lambda X_{G}+(1-\lambda) X_{B}\right)} \Leftrightarrow \lambda>\frac{I-\pi_{C}\left(X_{B}-c\right)}{\pi_{C}\left(X_{G}-X_{B}\right)\left(1-c / X_{B}\right)} \equiv \bar{\lambda}_{1} \\
& I-\pi_{C}\left(X_{B}-c\right) \text { : Minimum subsidy required to induce the B-type to exert effort. } \\
& \pi_{C}\left(X_{G}-X_{B}\right) \text { : Expected return differential (given the high effort level is chosen). } \\
& 1-c / X_{B} \text { : Maximum } \alpha \in I C_{B}
\end{aligned}
$$

b) Regarding the second condition, since $X_{G}>X_{B}$ and $0 \leq \lambda \leq 1$, at any given $(\alpha, D)$ pair, $u_{G}^{A}$ is flatter than $P Z P_{L}$. Therefore, it suffices to show that the intersection point of $u_{G}^{A}$ with the horizontal axis lies to the left of that of $P Z P_{L}$.

The intersection point of $P Z P_{L}$ with the horizontal axis is given by:

\footnotetext{
${ }^{39}$ These equilibria also obtain in a two-stage signalling or screening game.
} 


$$
D=\frac{I}{\lambda \pi_{C}+(1-\lambda) \pi_{0}}
$$

Moreover, the expected utility of the G-type in equilibrium is given by:

$$
U_{G}^{*}=\left(1-\alpha^{*}\right) \pi_{C}\left(X_{G}-D^{*}\right)
$$

At $\alpha=0$, the G-type's expected utility is:

$$
\left(U_{G}\right)_{\alpha=0}=\pi_{C}\left(X_{G}-D\right)
$$

Setting $U_{G}^{*}=\left(U_{G}\right)_{\alpha=0}$ and using the expressions for $\alpha^{*}$ and $D^{*}$, we obtain:

$$
D=\frac{I-(1-\lambda) \pi_{C}\left(X_{B}-c\right)}{\lambda \pi_{C}}
$$

Hence, the second condition is satisfied if:

$$
\frac{I}{\lambda \pi_{C}+(1-\lambda) \pi_{0}} \geq \frac{I-(1-\lambda) \pi_{C}\left(X_{B}-c\right)}{\lambda \pi_{C}}
$$

Let $f(\lambda)=\frac{I-(1-\lambda) \pi_{C}\left(X_{B}-c\right)}{\lambda \pi_{C}}$ and $\quad g(\lambda)=\frac{I}{\lambda \pi_{C}+(1-\lambda) \pi_{0}}$

then $\quad f^{\prime}(\lambda)=-\frac{1}{\lambda^{2} \pi_{C}}\left[I-\pi_{C}\left(X_{B}-c\right)\right]<0, \quad f^{\prime \prime}(\lambda)=\frac{2}{\lambda^{3} \pi_{C}}\left[I-\pi_{C}\left(X_{B}-c\right)\right]>0$

Since, by assumption, $I-\pi_{C}\left(X_{B}-c\right)>0$.

Also, $\quad g^{\prime}(\lambda)=-\frac{\left(\pi_{C}-\pi_{0}\right) I}{\left[\lambda \pi_{C}+(1-\lambda) \pi_{0}\right]^{2}}<0, \quad g^{\prime \prime}(\lambda)=\frac{\left(\pi_{C}-\pi_{0}\right)^{2} I}{\left[\lambda \pi_{C}+(1-\lambda) \pi_{0}\right]^{3}}>0$

Since $\pi_{C}>\pi_{0}$, both $f(\lambda)$ and $g(\lambda)$ are strictly decreasing and strictly convex. 
Furthrermore, $f(\lambda) \leq g(\lambda) \Rightarrow \lambda \leq 1$ and $\lambda \geq \frac{I-\pi_{C}\left(X_{B}-c\right)}{\left(\pi_{C}-\pi_{0}\right) \frac{\pi_{C}}{\pi_{0}}\left(X_{B}-c\right)} \equiv \tilde{\lambda}$

Since i) $0 \leq \lambda \leq 1$, ii) both $f(\lambda)$ and $g(\lambda)$ are continuous, strictly decreasing and strictly convex, iii) $f(\lambda) \leq g(\lambda)$ for $\lambda \geq \tilde{\lambda}$ and $f(\lambda)>g(\lambda)$ for $\lambda<\tilde{\lambda}$, then $f(\lambda) \leq g(\lambda)$ for all $\lambda \in[\tilde{\lambda}, 1]$. Therefore, $u_{G}^{A}$ does not cut $P Z P_{L}$ for any $\lambda \in\left[\bar{\lambda}_{1}, 1\right]$ if and only if:

$$
\bar{\lambda}_{1} \geq \tilde{\lambda} \Leftrightarrow \pi_{0} X_{G} \leq \pi_{C} X_{B}
$$

By Assumption 1, this condition is always satisfied. Q.E.D.

Proof of Proposition 5: Similarly, the pooling equilibrium of Proposition 5 exists if the following two conditions are satisfied:

$$
\begin{gathered}
\lambda \geq \bar{\lambda}_{2}=\lambda^{S P} \\
\pi_{C} X_{G}-\pi_{0} X_{B} \geq C
\end{gathered}
$$

By Assumption 1, the second condition is always satisfied. The first condition $\left(\lambda \geq \bar{\lambda}_{2}=\lambda^{S P}\right.$ ) is identical to that the social planner faces. Therefore, a debt-warrant combination can implement the optimal contract as a competitive equilibrium. Q.E.D.

\section{Separate Debt and Equity (Warrant) Markets}

The analysis in the text assumed that the required amount of funds I is provided by the same financier who purchases both debt and equity (warrant). In this appendix, we show that all the results go through even if the buyer of debt and the buyer of equity (warrant) are different (debt and equity (warrant) markets are separate). It suffices to show that the zero-profit curves of an equity-buyer (a warrant-buyer), a debt-buyer and a financier purchasing both debt and equity (warrant) coincide. The following assumptions are made:

i) The project is indivisible.

ii) Entrepreneurs cannot lend and the consumption good is perishable.

iii) Debt and equity (warrant) markets are perfectly competitive.

The first assumption implies that the entrpreneurs borrow at least I. The second implies that no entrepreneur will borrow more than I. Therefore, entrepreneurs borrow just I. Given these three assumptions, we have:

$$
I_{D}+I_{E}=I
$$




$$
\begin{gathered}
P_{D F}=\left\lfloor\lambda \pi_{j}+(1-\lambda) \pi_{k}\right\rfloor D-I_{D}=0, \quad j=C, 0, \quad k=C, 0, \\
P_{E F}=\alpha\left\lfloor\lambda \pi_{j}\left(X_{G}-D\right)+(1-\lambda) \pi_{k}\left(X_{B}-D\right)\right\rfloor-I_{E}=0 \\
P_{F}=\lambda\left\lfloor\alpha \pi_{j}\left(X_{G}-D\right)+\pi_{j} D\right\rfloor+(1-\lambda)\left[\alpha \pi_{k}\left(X_{B}-D\right)+\pi_{k} D\right]-I=0
\end{gathered}
$$

where $I_{D}$ : Amount the entrepreneur borrows from the debt-financier

$I_{E}$ : Amount the entrepreneur borrows from the equity-financier

$P_{D F}$ : Expected profit of the debt-financier

$P_{E F}$ : Expected profit of the equity-financier

$P_{F}$ : Expected profit of a financier purchasing both debt and equity

Using (A20), (A21), (A22) and (A23) we obtain:

$$
\begin{gathered}
\left.\lambda \mid \alpha \pi_{j}\left(X_{G}-D\right)+\pi_{j} D\right]+(1-\lambda)\left[\alpha \pi_{k}\left(X_{B}-D\right)+\pi_{k} D\right]-I \\
=P_{E F}=P_{D F}=P_{F}=0
\end{gathered}
$$

That is, the zero-profit curves of an equity-financier, a debt-financier and a financier purchasing both debt and equity coincide. Therefore, the pooling equilibrium of Proposition 4 obtains regardless of whether the same investor purchases both debt and equity and provides the required amount I or the debt-financier and the equity-financier are different (bond and equity markets are separate).

Similar results can be derived for the individual zero-profit curves. Also, all the results go through if debt and warrants are issued instead of debt and equity. 


\section{References}

Brennan, Michael and Alan Kraus, 1987, Efficient financing under asymmetric information, Journal of Finance 42, 1225-1244.

Casamatta, Catherine, 2003, Financing and advising: Optimal financial contracts with venture capitalists, Journal of Finance 58, 2059-2086.

Cho, In-Koo and David M. Kreps, 1987, Signalling games and stable equilibria, Quarterly Journal of Economics 102, 179-221.

Constantinides, George and Bruce D. Grundy, 1989, Optimal investment with stock repurchase and financing as signals, Review of Financial Studies 2, 445-465.

Cornelli, Francesca and Oved Yosha, 2003, Stage financing and the role of convertible securities, Review of Economic Studies 70, 1-32.

De Meza, David and David C. Webb, 1987, Too much investment: A problem of asymmetric information, Quarterly Journal of Economics 102, 281-292.

De Roon, Frans and Chris Veld, 1998, Announcement effects of convertible bonds loans and warrant-bond loans: An empirical analysis for the Dutch market, Journal of Banking and Finance 22, 1481-1506.

Diasakos, Theodoros and Kostas Koufopoulos, 2008, Equilibrium and optimal mechanisms in economies with adverse selection, working paper.

Fama, Eugene F. and Kenneth R. French, 2002, Testing trade-off and pecking order predictions about dividends and debt, Review of Financial Studies, 15, 1-33.

Fama, Eugene F. and Kenneth R. French, 2005, Financing decisions: Who issues stock?, Journal of Financial Economics, 76, 549-582.

Green, Richard, 1984, Investment incentives, debt, and warrants, Journal of Financial Economics 13, 115-136.

Hellwig, Martin, 1987, Some recent developments in the theory of competition in markets with adverse selection, European Economic Review 31, 319-325. 
Innes, Robert, 1990, Limited liability and incentive contracting with ex ante action choices, Journal of Economic Theory 52, 45-67.

Jensen, Michael and William Meckling, 1976, Theory of the firm: Managerial behavior, agency costs, and capital structure, Journal of Financial Economics 3, 305-360.

Myers, Stewart and Nicholas Majluf, 1984, Corporate financing and investment decisions when firms have information investors do not have, Journal of Financial Economics 13, $187-221$.

Rajan, Rughuram G., and Luigi Zingales, 1995, "What do we know about capital structure? Some evidence from international data, Journal of Finance 50, 1421-1460.

Rothschild, Michael and Joseph Stiglitz, 1976, "Equilibrium in Competitive Insurance Markets: An Essay on the Economics of Imperfect Information," Quarterly Journal of Economics, 90, 629-649.

Schmidt, Klaus M., 2003, Convertible securities and venture capital financing, Journal of Finance 58, 1139-1166.

Stein, Jeremy C., 1992, Convertible bonds as backdoor equity financing, Journal of Financial Economics 32, 3-21.

Titman, Sheridan and Roberto Wessels, 1988, The determinants of capital structure choice, Journal of Finance 43, 1-19.

Wilson, Charles, 1977, A model of insurance markets with incomplete information, Journal of Economic Theory 16, 167-207. 